\title{
Is Architecture Connected with Intangible Cultural Heritage? Reflections from Architectural Digital Documentation and Interactive Application Design in Three Aegean Islands
}

\author{
Pavlos Chatzigrigoriou ${ }^{1}$, Vasiliki Nikolakopoulou $\left.{ }^{1, *} \mathbb{(}\right)$, Theodoros Vakkas ${ }^{2}$, Spyros Vosinakis ${ }^{1}(\mathbb{D}$ and \\ Panayiotis Koutsabasis ${ }^{1}$ D \\ 1 Department of Product \& Systems Design Engineering, University of the Aegean, 81100 Mitilini, Greece; \\ pavlos.chatzi@aegean.gr (P.C.); spyrosv@aegean.gr (S.V.); kgp@aegean.gr (P.K.) \\ 2 Geospatial Enabling Technologies, 18344 Moschato, Greece; tvakkas@getmap.gr \\ * Correspondence: v.nikolakopoulou@aegean.gr
}

Citation: Chatzigrigoriou, P.; Nikolakopoulou, V.; Vakkas, T.; Vosinakis, S.; Koutsabasis, P. Is Architecture Connected with Intangible Cultural Heritage? Reflections from Architectural Digital Documentation and Interactive Application Design in Three Aegean Islands. Heritage 2021, 4, 664-689. https://doi.org/10.3390/heritage 4020038

Academic Editor: Nicola Masini

Received: 9 March 2021

Accepted: 19 April 2021

Published: 21 April 2021

Publisher's Note: MDPI stays neutral with regard to jurisdictional claims in published maps and institutional affiliations.

Copyright: (c) 2021 by the authors. Licensee MDPI, Basel, Switzerland. This article is an open access article distributed under the terms and conditions of the Creative Commons Attribution (CC BY) license (https:// creativecommons.org/licenses/by/ $4.0 /)$.

\begin{abstract}
The research project "Mouseion Topos" (in English: "Museums Place"), focusing on traditional local settlements situated at three Aegean islands, aims to contribute to the promotion of their physiognomy and intangible cultural heritage by connecting regional museums with each settlement. The present article, part of the project's initial phase, via the application of the HERMeS methodology (version 1 and 2) and the development of the associate digital documentation tools, identifies and records the architectural and urban elements influenced by each settlement's intangible cultural heritage as listed by UNESCO and presented by their corresponding museums. The research findings revealed connections between the museums' content and the documented tangible heritage based on the formulated conceptual and heatmaps, which can be used at the early design stages of the current project's interactive applications, especially in mobile tours. Finally, the research findings verify that despite the limitations and issues for further research, the introduced HERMeS methodology and digital tools are reliable and contribute to the respective field's theory. The paper also provides beneficial deliberation on digital architectural heritage documentation methods and interactive technologies, highlighting points and areas of interest that the tourist industry, technology designers, museum curators, and architects can employ.
\end{abstract}

Keywords: architectural heritage; intangible cultural heritage; digital heritage; spatial data infrastructure; museum; marble craftsmanship; olive oil industrial production; mastic cultivation; physiognomy; HERMeS methodology; UNESCO; heritage management

\section{Introduction}

Recording and preserving buildings and protecting a place's cultural heritage are crucial because it leads to many conclusions about the evolution of our culture. In fact, the urban environment's very structure is intrinsically connected with almost all forms of memory: cultural, communicative, collective, individual, institutional, informal, public, and private. While old sites are forgotten, new representations emerge, and ultimately, the landscapes of memory created, are scattered throughout the city depending on the formal urban design or traditional practices of different communities. To that matter, these landscapes of memory require the recording, control, and classification of representations of space. Therefore, in terms of its relationship with time, memory is inextricably linked to space [1].

'Space', a tool and, at the same time, an object of analysis, is not perceived as a given set of natural characteristics but as a result of a hover between matter and meaning, as a complex and diverse series of documentation of different elements: natural, mythological, symbolic, imaginary, linguistic, representational [2]. Undoubtedly, space is an abstract condition. Its value is based on its content; by itself, it has neither character nor particular 
physiognomy. These two facets appear from the moment that human presence and activity concretize the space by filling it with humanized forms, functions, dreams, expectations, feelings, and meanings. It is then that space has been turned into a place [3]. An essential element of a place is its buildings, reflecting an expression of the societies and the people who created them. All in all, buildings are evidence of cultural and social changes. Their design, construction, use, abandonment, and eventually their decay demonstrate the pace of societal growth and decline. The tourism industry relies on the observation of buildings (mainly historical or monumental) and the emotions they can evoke to the visitor; researchers have paid increasing attention to understand and enhance the tourism experience as a critical concept in tourism marketing [4]. Lynch [5] suggests viewing cities as "works of art" on a larger scale. However, they are temporary and cannot change with the rhythms produced by other forms of art, such as music. Over time, various people will experience the city in entirely different ways [5]. Ingold [6] characteristically states that "building is a process that goes on as long as people live in an environment. It does not start with a plan we have conceived in advance and ends with a ready-made object. The 'final form' is only fleeting."

However, the idea of the past is not only integrated into space but also in cultural practice. Data collection for significant buildings, complexes, settlements, areas, and other objects during the architectural documentation concerns both evident and hidden data. From the visible signs left by the ruins of a settlement to the stories of the community of people associated with them, their music, songs, art, crafts and artefacts, their social and religious ceremonies-all of the above make up a hive of information and experience, capable of making it a genuine cultural entity [7]. Intangible cultural heritage can be perceived as a performance or expressive collection of the culture, be it a specific small or big group of people. The recording of traditions with the participation of a broader social web associated with these traditions, as well as with other forms of oral transmission of knowledge (customs, rituals, artistic expressions, craftsmanship), have become the subject of modern dialogue and research [8-12] in the field of museology. Museums showcasing intangible cultural heritage are invited to alter their overall curatorship in contrast to museums exhibiting movable tangible heritage. They represent "museums of ideas, communities, and stories" [8]. Thus, exhibitions of the respective museums increasingly redirect their focus from the mere observing and strictly "not touching" of the exhibited artefacts approach to encouraging tactile engagement and interaction. In this way, a museum comes closer to its audience, fulfilling its primary social purposes.

This very connection between place and cultural practice is a fundamental concern for museums that highlight the invisible, intangible heritage of a cultural place, a concern that is equally crucial for our research project, "Mouseion Topos". In the case of this project, we focus on recording the cultural characteristics of three traditional settlements situated in three islands of the Aegean: Pyrgos (Tinos), Agia Paraskevi (Lesvos), and Olympoi (Chios). To that end, an interdisciplinary team of specialists was assembled, consisting of interaction designers, architects, cultural heritage professionals, curators, and engineers. This research team explores possible technological applications digitally connecting museums that showcase UNESCO-enlisted intangible heritage, with their cultural places: the Museum of Marble Crafts in Pyrgos, the Museum of Industrial Olive Oil Production in Agia Paraskevi, and the Chios Mastic Museum, belonging all to the Piraeus Bank Group Cultural Foundation (PIOP) [13] in Greece. A visualization of the methodological framework of the project "Mouseion Topos" is presented in Figure 1. The present article is part of the initial phase (green colored frame) of the project, related to the architectural documentation of the three specific traditional settlements, respectively associating them with a museum that demonstrates their intangible cultural heritage. More precisely, aiming to promote traditional settlements' physiognomy and intangible cultural heritage, as well as to support the interactive design teams, the objective of this paper is defined as follows: via the application of the research methodology-HERMeS v.1 and v.2-and the development of the associate digital documentation tools (presented in Section 3), to identify and record architectural 
and urban elements influenced by each settlement's intangible cultural heritage as listed by UNESCO and hosted by their corresponding museums.

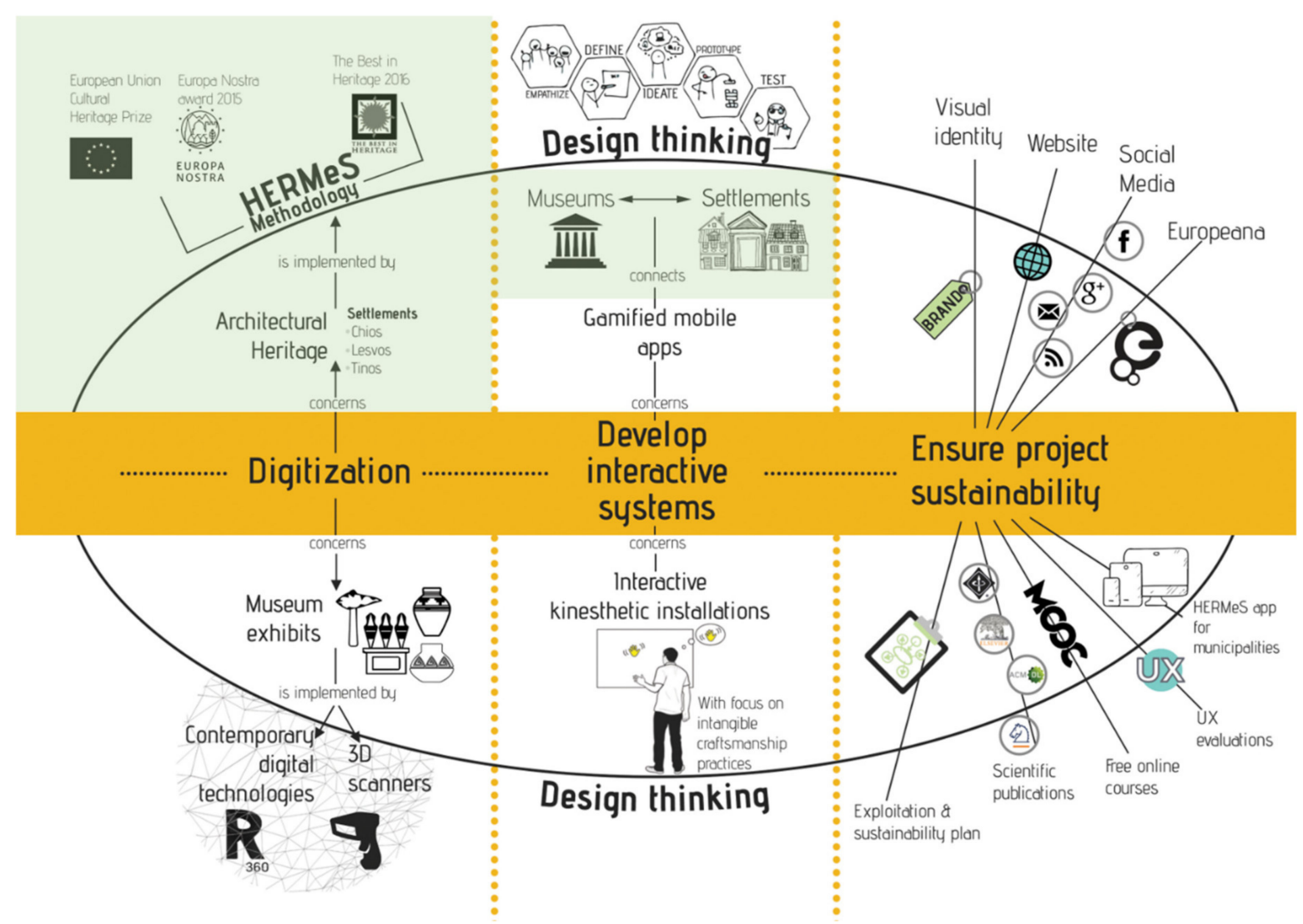

Figure 1. Visualization of the methodological framework of "Mouseion Topos". This paper focuses on the greencolored frame.

To achieve the above-stated objective, we systematically studied the museums' content and the respective traditional settlements and digitally recorded the latter. To do this, we first adopted the HERMeS methodology [14], granted with the Europa Nostra award, and developed a digital documentation tool to record the significant buildings and their architectural characteristics. The aim was to determine the particular architectural and urban elements influenced by the place's intangible cultural heritage, as it is inscribed and curated by the three PIOP Museums focusing on: marble craftsmanship, olive oil and its industrial production, and mastic cultivation.

In the following Section 2 (Background and Literature Review), the article introduces the reader to basic concepts, such as tangible (built) and intangible cultural heritage, their connection to the notion of monumental site, and places' physiognomy. Section 3 presents the methodological approach used and proceeds with the presentation of the HERMeS methodology and its updated, more advanced version 2, towards traditional settlements' architectural documentation and the associate digital tool's design and development. The section concludes by showing the integration of this tool into a Spatial Data Infrastructure (SDI) portal, and the possibility of generating ad hoc custom-made maps. Section 4 outlines the conclusions that emerge from the study and documentation of each settlement's architectural (tangible) and intangible cultural heritage. Specifically, it attempts to relate the geospatial information gathered through the architectural documentation with conceptual mapping schemes that connect the museum's content with the settlement's points of interest and representative buildings, contributing to understanding its physiognomy. Section 5 discusses the methodological approach's main research findings, the conclusions, the limi- 
tations, and the new prospects introduced with the obtained data. Concluding, Section 6 deliberates on valuable lessons learnt in the process while highlighting the growing need for additional research on the project's primary and encouraging outcomes.

\section{Background and Literature Review}

\subsection{Tangible, Intangible Cultural Heritage, and Monumental Places}

The interest in the study of historic buildings first appears during the Renaissance. The study of ancient texts and the return to classical values of the past gave rise to the research and analysis of ancient monuments. However, the genuine interest in monuments appears in the 18th and 19th centuries, through social ferment [15,16]. In 1931, the issue of "recording" monuments was introduced, and the "Charter of Athens" [17] raised the issue of saving their surrounding area as well, thereof, deliberating on how to intervene in the monument's environment. The "Charter of Athens" places the wider urban environment's cultural elements in a framework of urban development planning perspective. In this sense, it can be considered a milestone in scientific thinking to protect heritage. The first discussions about "places" were initiated, and the limitations of protection started being explored: Can a city that does not have "first-class" monuments be protected? [18]. In 1993, the second ICOMOS conference introduced inventory listings for historic building stocks, as well as scholarly work supporting the need to approach historic buildings and ensembles, not only as elements of cultural and architectural heritage but also as "resources" [19].

The monument of the built environment (architectural heritage) has a significant and essential role in promoting human memory and functioning as a link between the present and the past. Specifically, this role is twofold: it answers to the present's problems and maintains memories. When the monument is placed inside the urban environment, it charges memories, sparks the imagination, and creates specific psychology in the human being $[20,21]$. However, what happens in the case of traditional settlements and the rural environment? What dimensions do the concepts "monument" and "place" acquire in this context? What makes a building monumental, and why are entire settlements considered memorable? How can we define them, and how does the intangible cultural heritage of a settlement affect its construction and overall form?

According to the UNESCO Convention on the Safeguarding of Intangible Cultural Heritage (Paris, 2003) the "intangible cultural heritage" means "Practices, representations, expressions, knowledge, skills—as well as instruments, objects, artefacts, and cultural spaces associated therewith-that communities, groups and, in some cases, individuals recognize as part of their cultural heritage"(Article 2). The Convention went one step further, giving, among other things, paramount importance to the communities of bearers of intangible cultural heritage. The idea of intangible cultural heritage and the attempt to define it is rooted in the emergence of a holistic approach to the documentation, restoration, and promotion of monuments and monumental sites. This emergence is linked with the word "monument", the search of its meaning and interpretation by the people involved in the documentation of the past. The term "monument" has been re-contextualized many times following the evolution of the concept "heritage" [22] and its semantic transfer to "cultural heritage". The main reason was the need to put tangible heritage into a broader context and to connect it with the natural environment and its intangible aspects: spiritual, political and social [22-24]. The existing natural and cultural diversity among the nations of the world, and the idea that intangible cultural heritage is the one that pre-exists before its materialization into tangible $[25,26]$, led to a more anthropological and holistic approach to the concept, and at the same time, to the emergence of the term "monumental place". Therefore, a monument can be approached as a whole, within a place with a soul-a genius loci [27].

The monumental, historical sites, on the one hand, are places of cultural identity, with a strong imprint of human influence on them. While the material part of these spaces may leave its mark over time, the intangible element most closely associated with its creator may not always survive. The survival of the intangible element depends on the 
transmission of knowledge (oral or creative) that contributes to the creation of its material manifestation (e.g., craft, song), and the authentic, qualitative, symbolic, and historical values that reflect its purpose. It is a transmission of practices, knowledge and skills that incorporate a form of memory into the material manifestation, indicating the relationships humans develop with it through a shared system of ideas and beliefs, i.e., social and cultural structures [24]. Thus, values and memory can turn a set of marble stones, metals, and rocks into a monumental site. As a structure and a carrier of the above, culture acquires historical significance and becomes a "memorable" asset of the intangible heritage of humanity that needs safeguarding. Such examples are adding marble craftsmanship [28] and mastic cultivation [29] to the corresponding UNESCO list of the intangible cultural heritage of the world.

On the other hand, the monument could only be perceived as a "work of art" in a specific cultural environment. Heidegger uses the word "bewahrung" which means "preservation" but has the same root as the word "wahrheit" which means "truth", giving to "preservation" of the direction of preserving the "truth" of the monument [30]. Could that apply to the case of the monumental, historic site? How do we recognize the "truth" of a monumental site? How can the intangible cultural heritage of a monumental site reinforce the recognition of its "truth"? Could this be applied to the case of our three traditional settlements, assuming that they constitute monumental sites because of their worldly-recognized intangible cultural heritage?

By and large, the issue of authenticity becomes the central inquiry, even in museums. Intangible cultural heritage appears more like an interactive medium where the past is "presented" to the present, as a dynamic engagement that relates traditional culture to modern reality [8,31]. In this process, the carriers of tradition are the members of the community; it is they who determine the authenticity, not so much the experts or the respective policymakers. "How are these bodies involved and presented in the modern museum practices?" could be a question addressed to the 21st-century museums and museology, in the multifaceted and challenging task of preserving and highlighting the intangible cultural heritage of a place.

Correspondingly, this abovementioned challenge is faced in the case of the present project as well. "Mouseion Topos" strives for the authenticity of the local, relying, in fact, on the authenticity of the relationship between architecture and place, which provides a timeless quality commitment that can be discovered in the physiognomy of the settlement. Physiognomy emanates from the converging involvement of people and their artefacts in the formation of the traditional settlements. This convergence signifies the presence of genuine experience, the absence of which would weaken human-place relations and lead to a loss of authenticity. Therefore, studying the intangible cultural heritage of a settlement can update its architectural recording and documentation. Precisely, in this case, the authenticity of a place, as presented by communal bodies, could unfold how "the form of an artefact is related to (the process of) its creation" [32].

\subsection{Physiognomy of Places}

According to the previous section, the need for the protection of the character of historic places and their monuments is undeniable. Nevertheless, highlighting the character of a city, a residential ensemble or a traditional settlement is a laborious task. It presupposes the inquiring and the recording of the "character" through a process that will attribute the "physiognomy" of the place. Physiognomy concerns the uniqueness, identity, and even the "personality" of a place, as it is formulated and appears through its characteristics. It refers exclusively to the uniqueness of the entity of a place. Thus, it could be argued that each form of perception (sight, hearing, touch, smell, taste), and the aesthetic and logical perception of the elements of a place, contribute to shaping the knowledge and experience of the place [18]. However, the place is a specific space with its historical phases that sculpt its character, and it includes the natural elements (flora, fauna, soil, materials) and the anthropogenic materials and intangible elements: human emotions, actions, and expressions. 
Indeed, people are attached to their places, as the place derives its very existence from the people who shaped it over time. At the same time, people adopt intangible elements that shape their personality from their place's collective consciousness [33].

In the perceptual reading of the city's physiognomy, most scholars use it as a field of reference to the historic city in which they recognize aesthetic qualities. The perception of the physiognomy of historic cities is mainly visual and kinesthetic according to most scholars (Sitte, Unwin, Cullen, Lynch, but also by many younger scholars of the city, such as Rapoport, Meiss, Panerai, and Moudon) [34]. Comparison is at the core of perceptual reading and acts on an unconscious level. Aesthetic appreciation has a personal character but also contains collective elements. Especially in tourism, aesthetics is an essential added-value component in tourists' experience and may serve as a satisfier of their needs, influencing tourists' behavioral attributes, such as loyalty. Research proves that dimensions uniquely relevant to the tourism experience-such as Scale, Sound, Uniqueness, Authenticity and Time-appear to be more influential in tourists' aesthetic fulfillment [4]. Physiognomy is shaped by these dimensions and has a vital role in tourists' aesthetic judgment, especially in historical/traditional settlements where authenticity, uniqueness, time, and scale are a core part of their image. Therefore, the next question that reasonably arises is "How can one record the physiognomy of a historical place, primarily to promote and also protect it?".

In the present paper, before developing a methodology promoting and preserving the historic settlements, we first apply architects' methods to digitally record aspects of the place's physiognomy - in our case, a traditional settlement—and its pathology state. The digital records obtained by such process can be reused by the project members to research and apply their potential integration into the final interactive applications that aim to transcend the "image of the settlement" as we studied and recorded it through our methodological approach.

\section{Methodological Approach}

\subsection{Research Process}

The applied methodology in this research-HERMeS version 1 (v.1) and version 2 (v.2) - integrates methods and practices from design, architecture, and landscape survey enhanced with Geographic Information System (GIS) as presented in SDI web portal (Figure 2). The team's interdisciplinary nature and the final delivery application call for the inclusion and selection of several processes used by the various involved disciplines, facilitating adopting of a common language. Moreover, it is an opportunity to research, apply, test, and reflect collaboratively on a new methodology to identify the advantages and disadvantages during its implementation.

At the first stage of the followed research process, architects, civil engineers, and surveyors of the team conduct a literature review on each of the three settlements' historical and architectural documentation, found mainly in national libraries of technical universities. The team studies, notes and classifies each settlement's various structural elements to facilitate their upcoming fieldwork. The HERMeS v.1 methodology, which will be presented briefly below, uses this classification and develops the fieldwork's digital documentation tool.

The second stage includes fieldwork, on-site recording and documentation of the structural features, identified in the literature review, by applying HERMeS v.1 mobile recording application presented in Section 3.3. Visiting and studying the museum content is part of the fieldwork since the museum constitutes a settlement component. Throughout the field visit, we record aspects of intangible cultural heritage via interviews with various stakeholders, such as the curators of the museum, citizens, and artisans in the case of Pyrgos, cultural associations in Agia Paraskevi, and mastic cultivators and local architects in Olympoi. Then, we transcribe and deliberate on the interviews with the project's researchers to understand which aspects of each settlement's specific intangible cultural heritage are most frequently materialized inside the settlement and comprise points of 
interest (POIs). The actual integration of this approach to the rest of the system is part of the final stage.

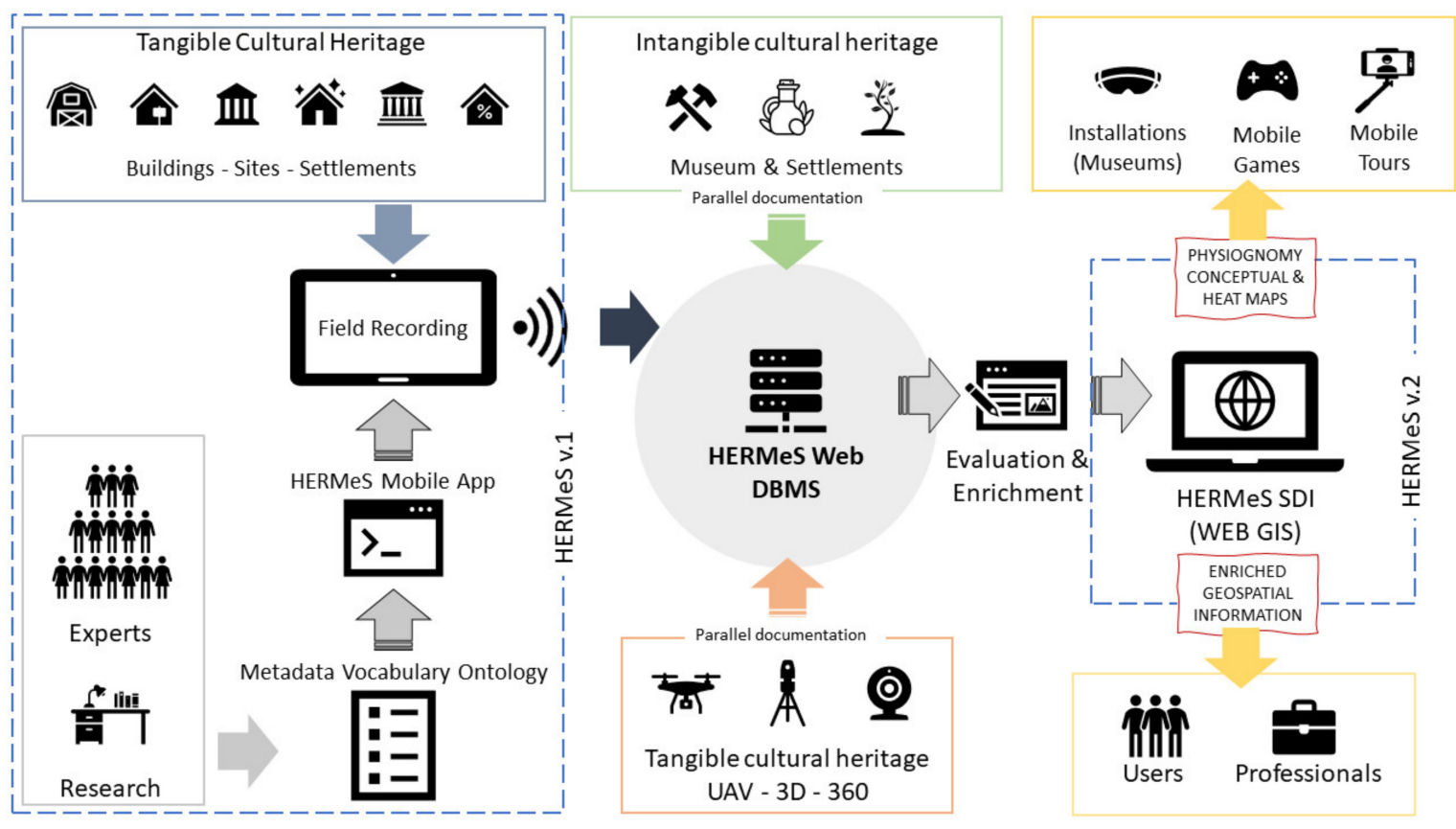

Figure 2. System architecture of HERMeS methodology: The first version of HERMeS (v.1) is enriched with parallel documentation (tangible and intangible cultural heritage). The new evaluated data of Web DBMS are used for developing HERMeS v.2 (SDI) which includes multiformat information (2D maps, 3D models, virtual street views, audio, video and texts) that are used to develop physiognomic conceptual and heatmaps, for tangible and intangible cultural heritage of each settlement.

The third stage refers to the recording data obtained through the on-site documentation of the settlements, its organization in the database (HERMeS Web DBMS), ways of mining this data and reusing it in GIS applications that will inform and enhance the meta-conceptual mapping process. For instance, a custom-made heatmap in this project is a GIS application that shows the settlement's areas where architectural and cultural heritage interest is concentrated.

The fourth (final) stage engages with the systematic study and reflection on the tangible and intangible aspects appearing both in the settlement and in the museum. To that end, the research and design team assume abductive thinking and collaborative sensemaking to synthesize $[35,36]$ the concepts of tangible and intangible cultural heritage derived through the field visits. The aim is to align the mental model [37-39] of each researcher regarding the connections she/he has already made between the museum's content and the fleeting image of the place. Concept schemes illustrate the team's connections and act as a canvas for future reference and conceptual design. The heatmaps and the concept schemes display the POIs inside the settlement where the mobile tour application should pass to provide the visitor with the optimum experience of the settlement's physiognomy.

\subsection{HERMeS (v.1 and v.2) Methodology and System Architecture}

Digital technology can be a catalyst in the handy recording, documentation, and preservation of tangible cultural heritage. HERMeS (v.1) started as a database system connected to a GIS developed to record essential and endangered buildings in Hermoupolis [14,40]. HERMeS (v.1) records and presents buildings' architectural value, as well as their typology and pathology, using a digital system (DBMS and GIS) that can be easily accessed and updated. HERMeS (v.1) also proposes a conservation plan for historic cities by ranking endangered buildings' jeopardy. For the latter, 'pathology'—a quality 
assessment factor-is insufficient to evaluate and rate the building's risk hazard. HERMeS (v.1) developed a multi-criteria model based on pathology indicators incorporated with architectural quality indicators and other social variables such as the area, the density, the usage of nearby buildings, and tourist attraction. The result is a point system leading to a conservation plan, giving the hierarchy of interventions to save the maximum architectural heritage with the minimum funds, protracting the risk of collapsing.

HERMeS is presented below in Figure 2, in its updated, more advanced version 2 (v.2). Conforming to the project "Mouseion Topos" and the need for on-site recording and documentation of the architectural features of the selected buildings at the three traditional settlements used as case studies, we now focus on the objective of the present paper: the evolution of the HERMeS system into a digital mobile application connected with a web database and a web GIS interface (SDI portal) (Figure 2). The system architecture is organized around a Geodatabase (Web DBMS), which serves the Web GIS Portal (SDI). The primary input to web DBMS comes from the field recording mobile application (HERMeS v.1), presented in the next Section 3.3. Parallel, additional information is collected digitally concerning intangible heritage (interviews, field research, literature) and tangible heritage (3D reconstruction, $360^{\circ}$ images, UAV ortho maps). All data are evaluated, brushed, refined and enriched by professionals (architects, engineers, cultural heritage experts, researchers). In the end, an SDI web portal integrates all information in a structured form for each settlement. The portal gathers data for other applications (interactive museum installations, mobile games and tours) to help users and professionals explore the historic settlements tangible and intangible heritage.

\subsection{HERMeS v.1: Mobile Recording Application}

The functional characteristics of the HERMeS mobile recording application are aiming to document architectural heritage and focus mainly on three categories related to the:

(a) Ability to record technical information regarding physiognomy for every settlement, using open text fields and controlled questions.

(b) Compatibility and interoperability with web database-GIS, compatibility with smart mobile devices, the ability for online communication and synchronization of data collected from all devices, offline operation, ability to record the location from GPS.

(c) Elements of usability and user experience (it remains as future work to evaluate the recording application's UX), such as the use of controlled value source vocabularies, indicative sketches, short helping texts, recording the different type of data (text, photos, videos, audio), different views of buildings (list, map, table) and editing previous recordings.

We designed the research fields (approximately 180 fields) to be recorded, deciding the metadata scheme and the controlled vocabulary for every settlement: Landscape and urban elements, History and interventions, Elements of architecture, Structural vulnerability, Materials, Pathology and Evaluation.

Thus, a team of trained architects recorded the historic buildings using the HERMeS mobile app. Parallel to that, extra documentation with $360^{\circ}$ cam and UAV was collected. On-camera interviews were also organized, aiming to collect intangible heritage stories. In total, 77 historic buildings were recorded: up to 450 photos, 10 videos and up to $1500360^{\circ}$ georeferenced photos were added to the database (HERMeS Web DBMS).

\subsection{HERMeS v.2: SDI Web Portal}

After evaluating and enriching of HERMeS Web DBMS data (Figure 2), we developed a particular SDI portal to present the gathered information in a formal and structured interface. The mainframe hosts a map (open street maps) with three groups of layers (one from each settlement) covering all the recorded buildings and the individual data for each one of them (Figure 3). 


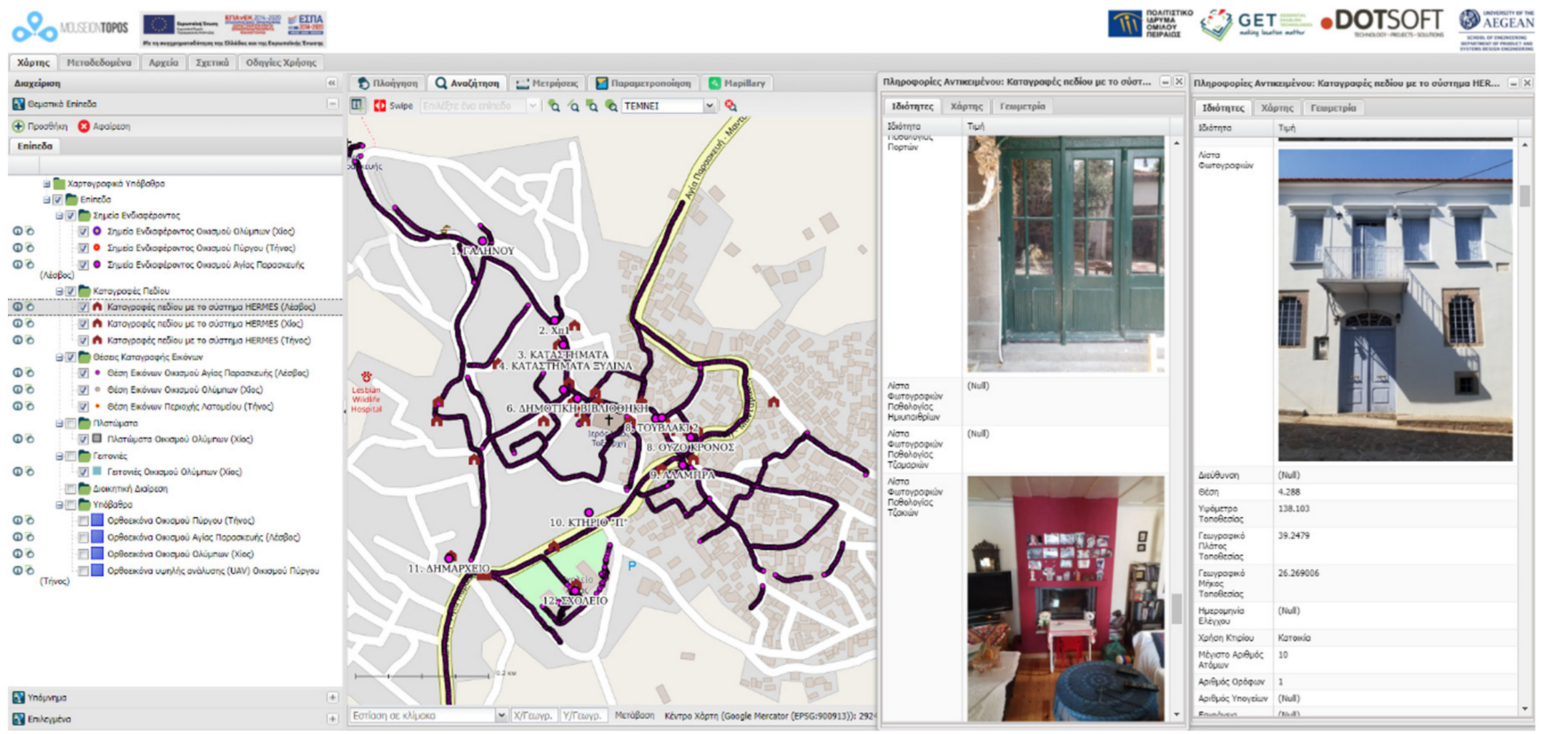

Figure 3. Web SDI: The settlement of Agia Paraskevi (Lesvos) with an example of the information windows for every building.

The information recorded with $360^{\circ}$ georeferenced photo spheres was also integrated into the SDI portal, using the Mapillary plugin (https:/ /help.mapillary.com/hc/en-us / articles/115001739989-Mapillary-JOSM-plugin, accessed on 27 November 2020). The settlements' physiognomy could be better perceived with movement in areas with the most exciting heritage elements, as was stated previously in this paper (Section 2.2). The $360^{\circ} \mathrm{im}-$ age spheres help to study details and experience a street view of the settlements (Figure 4).

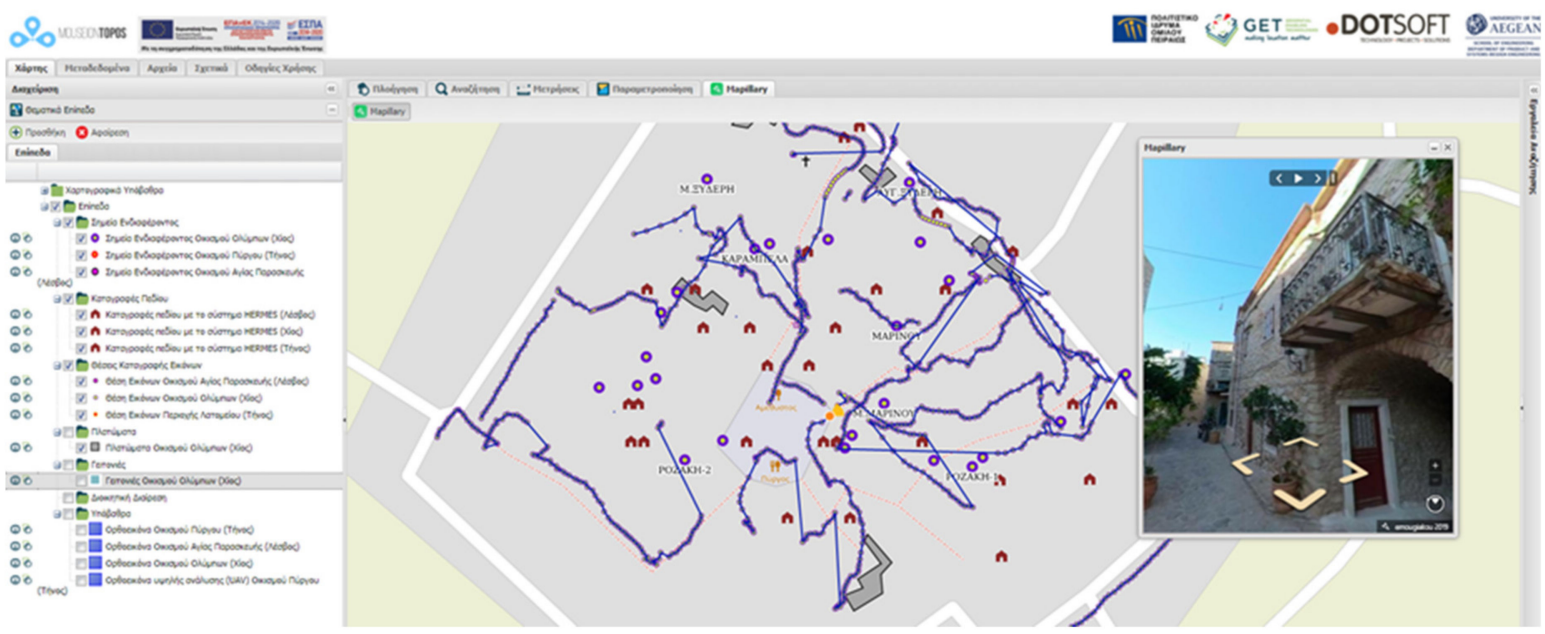

Figure 4. Web SDI: The settlement of Olympoi (Chios) with an example of the virtual tour.

At the end, UAV and photogrammetry techniques were employed to develop 3D reconstructions of traditional and historic houses. The 3D detailed model was hosted at the SDI portal through the Cesium plugin (https: / cesium.com/blog/2014/01/16/introducingcesium-plugins / accessed on 27 November 2020), showing accurate information and details of the local architecture. The 3D representation could help the user understand the forms, typology and local elements that make the settlement unique (Figure 5). 


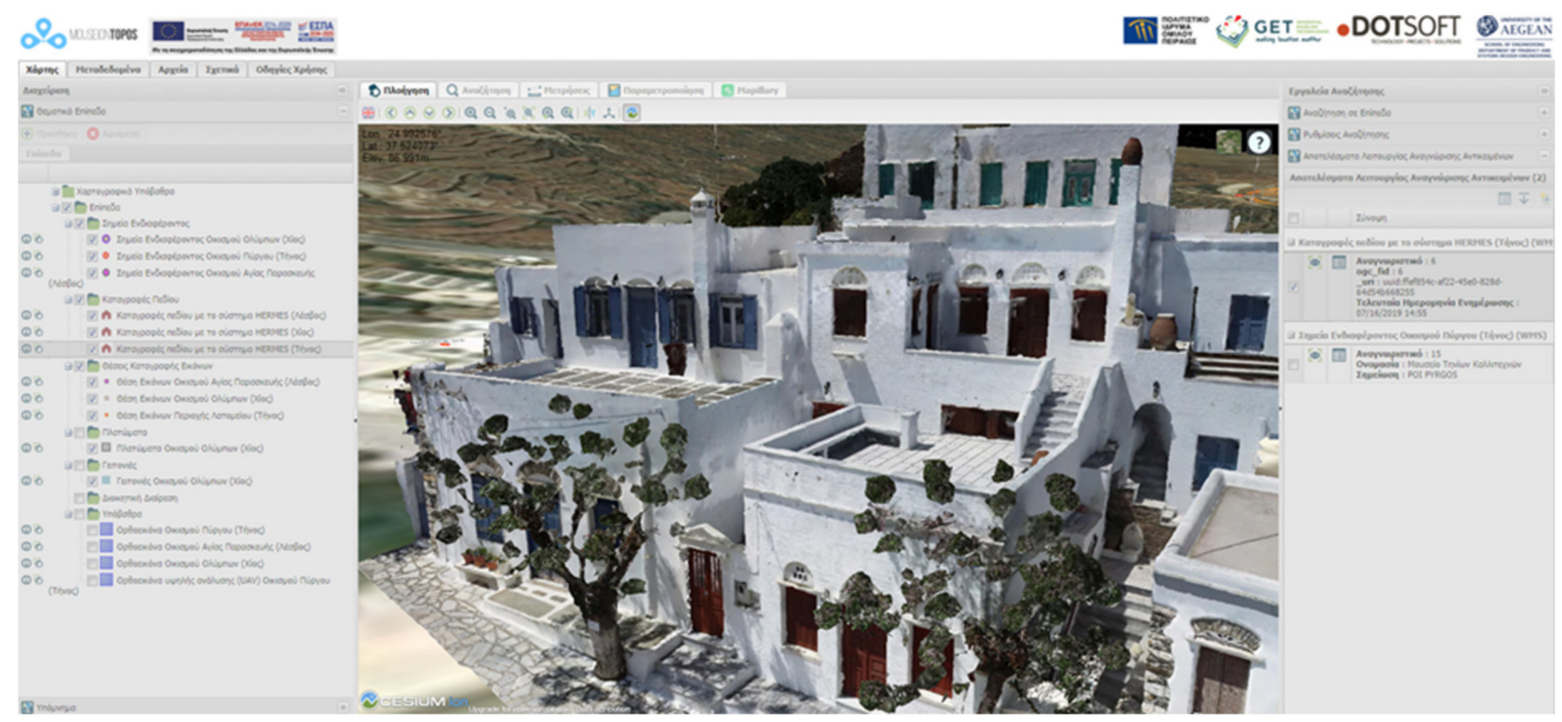

Figure 5. Web SDI: The settlement of Pyrgos (Tinos) with an example of the 3D reconstructed model.

\subsection{HERMeS SDI Heatmaps}

Using tools from the web SDI portal, it is possible to visualize the areas of each historic settlement where physiognomy (sense of the place) is more robust. This spatial algorithm is based on the location and the distance between the historical and traditional buildings that the HERMeS application recorded on-site. The result of the algorithm is a heatmap, where stronger physiognomy is red to yellow. Areas outside the heatmap (no color) are weaker in physiognomy elements (Figure 6).

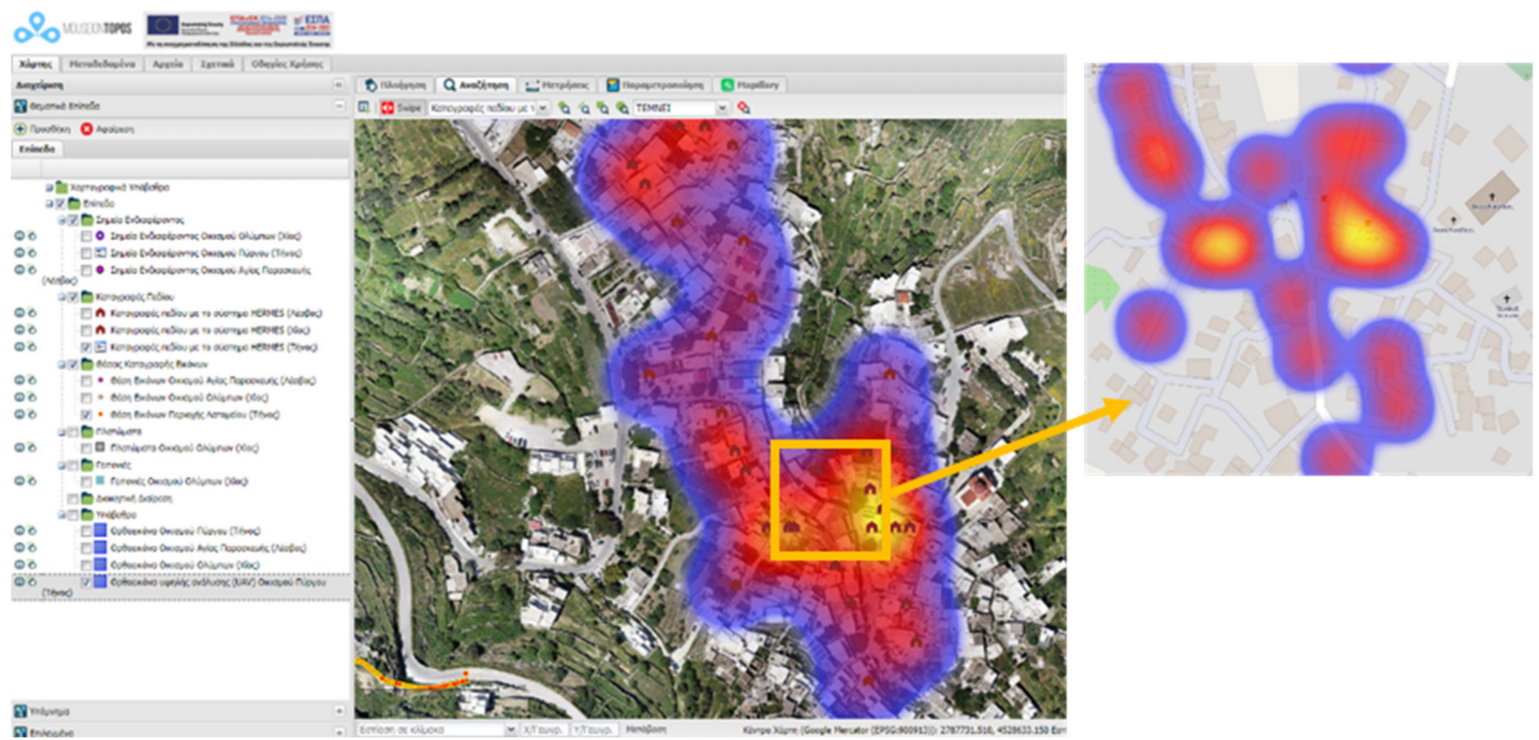

Figure 6. Heatmap of Pyrgos (Tinos) physiognomy, using historical buildings.

By adding another layer, the POIs, a new version of heatmap is produced (Figure 7). There is overlap in some areas in this version, but new sites are also added to the map (Museum, Quarry, Local craftsmen workshops). This version is proposed to be used in mobile games and tours, and kinesthetic installations, since it has more intangible heritage areas that cannot be experienced only by visual sense. 


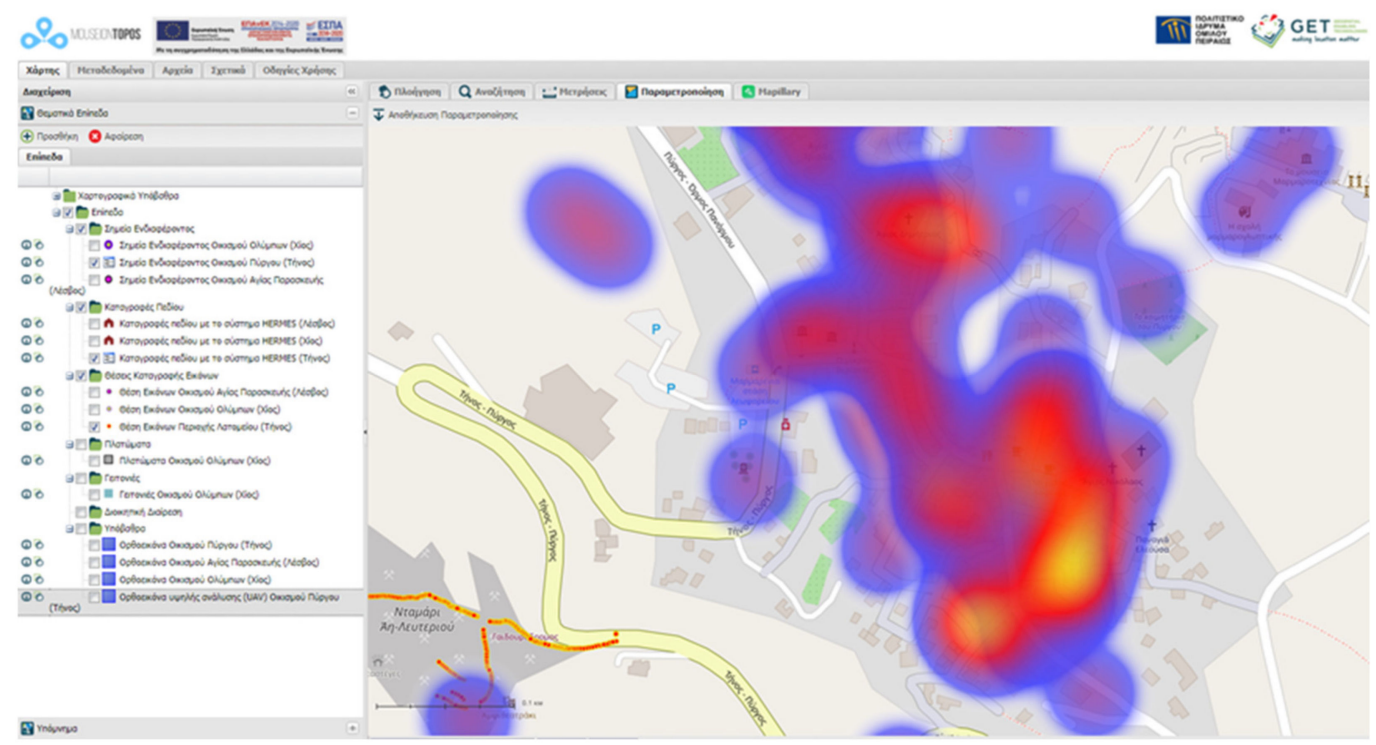

Figure 7. Heatmap of Pyrgos (Tinos) physiognomy, using historical buildings (field documentation) and POIs (field visits and interviews).

The three case studies are settlements where physiognomy is firmly attached to intangible heritage, as analyzed previously. The produced heatmaps help the designers recognize the areas that should be used in mobile applications and could be studied further as POIs connected to the museums and their installations/exhibitions. Physiognomy is better experienced with movement inside the settlement. Guiding visitors in the specific streets that the heatmaps cover will help them better understand each settlement's image and further connect it with its intangible heritage. The HERMeS SDI portal produces ad hoc heatmaps for every settlement of "Mouseion Topos". Those maps can be carefully studied and provide helpful information for designers of applications aiming to highlight tangible and intangible cultural heritage.

The following section shows representative examples from the three settlements where the architectural characteristics of their featured buildings have been recorded, while at the same time, introducing elements of intangible cultural heritage presented by the respective museums. In addition, the on-site work allowed the project team to experience the settlements and freely interview community members and other museum and settlement stakeholders. The latter helped the team understand the influences of the people's intangible manifestations observed inside the settlement. In combination with the produced heatmaps, the connections revealed ideal architectural routes inside each settlement.

\section{Connecting the Museum and the Settlement}

\subsection{Concept Mapping of Pyrgos and the Museum of Marble Crafts (Tinos Island)}

Tinos' contribution is particularly significant in the formation of Modern Greek art, predominantly sculpture and painting. Pyrgos is the birthplace of great artists and pioneers of contemporary Greek art, such as Nikiforos Lytras in painting, Dimitris Filippotis and Giannoulis Halepas in sculpture. It has a deep tradition in marble craftsmanship due to the abundance of raw material in the area. Landscaping may be an essential source of inspiration, too. The juvenile engravings on the settlement's marble-paved streets testify the local habitants' engagement with this material since their early childhood (Figure 8). It makes sense since the Tinian marble craftsmen acquire unique knowledge concerning marble and its properties, such as handling its veins. Moreover, they have developed the relevant skills for making the tools used both in marble-crafting and marblemining [41,42], a fact that has many implications in the social, cultural, and professional structures developed among the main occupations of the inhabitants. Still, the transmission 
of marble craftsmanship is based on a master-apprentice model $[42,43]$ through informal education, where the apprentice, after long and demanding training, finally receives complete expertise.
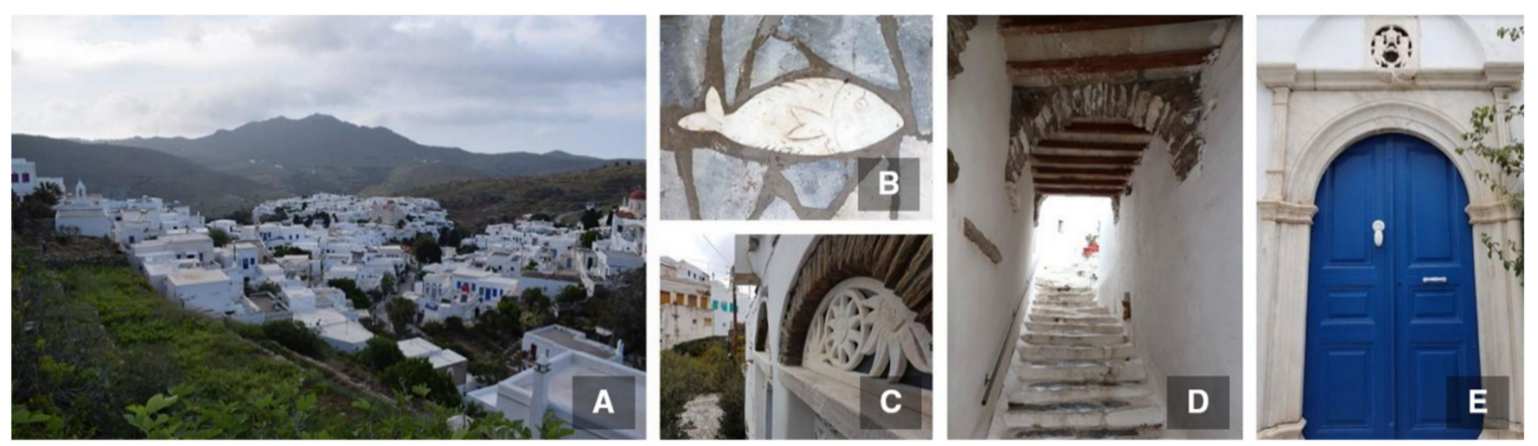

Figure 8. Pictures of the elements that define the physiognomy of Pyrgos: (A) the relief of the settlement; (B) an example of juvenile engravings (a fish); (C) a skylight; (D) a vault inside a small street; (E) a door and marble sign upon it.

Pyrgos is located at the western part of the island, about $27 \mathrm{~km}$ from the city of Tinos and a short distance from the coast, at an altitude of $130 \mathrm{~m}$. It is developed linearly, with its main square as a pivotal point and an age-old plane tree in the middle of the square. The village experienced growth during the 18th and 19th century due mainly to shipping and marble. Marble trade gave an economic outlet to the Tinian people that is reflected upon renovated houses with the engraved dates on marble signs upon doors (Figure 8) [44].

In this relief of the settlement, individual architectural features are observed, with the lintel frames or skylights being the most common in the whole settlement. The lintel frames cover the openings created above the lintel. The holes inside the relief arches of the openings and the lintel frames' perforated lids were used both for the ventilation of space and food storage. The lintels are representative samples of the island's artistic tradition in marble sculpture and craftsmanship, which is why it is met in various decorations. Other special architectural and morphological features found are the "fida", the "plangkouni", and the arches or "vaulta" (Figure 8).

Overall, what is acknowledged at every step in the settlement is the marble and the varied forms in the built space. The dominant intangible cultural heritage of the settlement, the Tinian marble craftsmanship, as also curated inside the Museum of Marble Crafts [41], classifies its creations (Figure 9) based on their use in:

1. Tools and utensils of everyday life, such as mortars, carved marble stones for cheese coagulation, sinks, etc.,

2. Architectural applications, such as paving, marble, columns, frames, porches, balconies, stairs, gables, but also iconostasis, pulpits, despotic thrones, shrines, church facades, vaults, catholic churches, etc., and

3. Marble sculptures or stone carvings, such as coats of arms, lintels and margins, skylights, fountains, tombstones, heroes, etc., that draw from religious, magical and oral traditions [43]. 

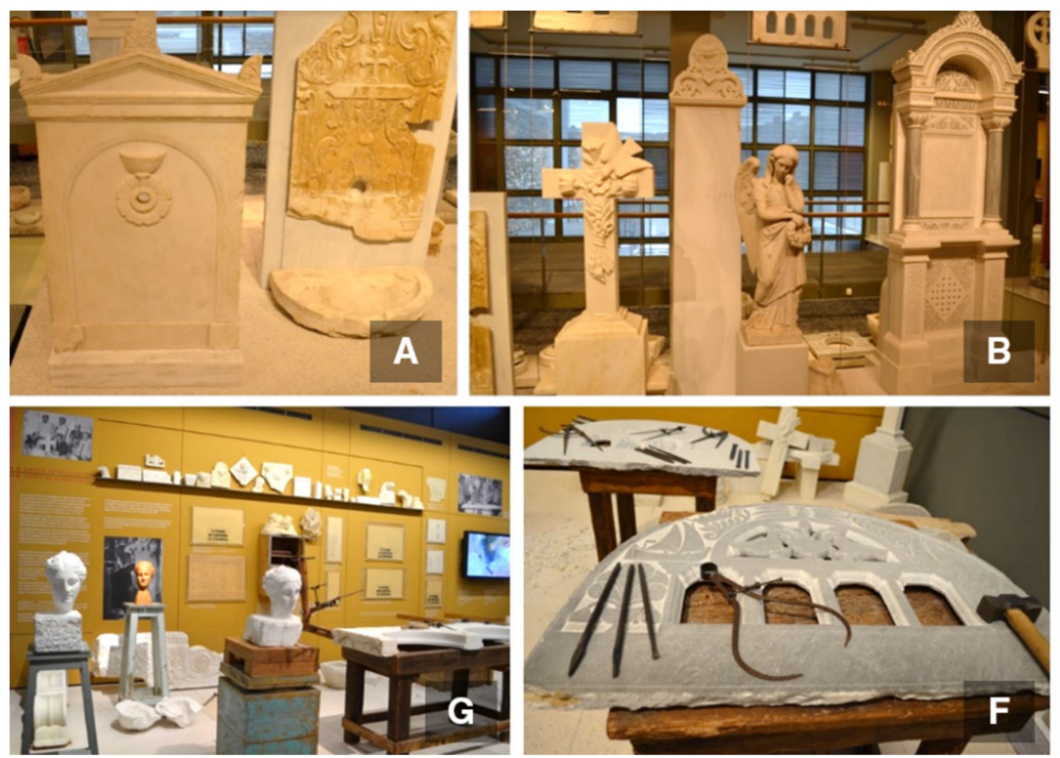
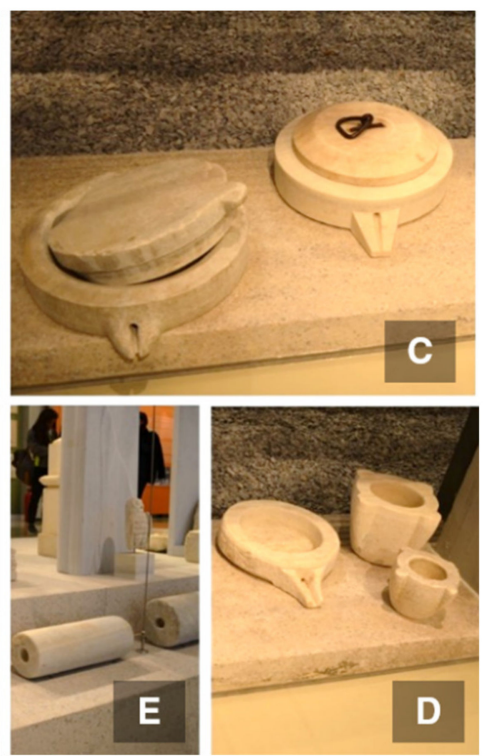

Figure 9. Examples of the creations of Tinian marble craftsmanship as presented inside the Museum of Marble Crafts, as essential elements of the physiognomy of the settlement: (A) fountains; (B) cross, sculpture, pulpit found at churches and cemetery; (C) examples of carved marble stones for cheese coagulation; (D) mortars; (E) example of korkokili or kolethro; (F) tool equipment of a marble craftsman creating a skylight; (G) simulation of a craftsman's workshop.

The local heritage is supplemented by the Museum of Marble Crafts, which-together with the quarry-constitute the village's extensions. Although literature stresses that geoheritage and stone heritage are directly linked to architectural heritage $[45,46]$ complicating our challenge for the traditional settlement of Pyrgos, the museum has managed to identify these links helping us to overcome this obstacle by using clear information provided by the museum.

The museum describes in detail and vividly, through mini-documentaries with local people's testimonies, the tool equipment and the techniques used to mine, manipulate, design, artistically create, and merchandise marble during the pre-industrial age. Many of the creations described above are featured inside the museum together with installations that simulate the work in a quarry, the workshops of marble artisans, the methods and tools they use, and designs and artistic creations. It also becomes apparent that the three significant occupations: the quarrier; the smith (who makes the tools); and the marble craftsman are coherent and co-dependent. Nonetheless, the museum's scope is to present the artefacts and the developed technology around Tinian marble and connect and reveal the social and economic context from which the craftspeople have advanced their workshops and contributed, through their work, to the overall image of their place. Consequently, the connections arise among the built environment, the specifically developed skills (craftsmanship) of the people, and the social and cultural structure developed. The abovementioned will function as a conceptual map for the respective interactive applications of the project.

More specifically, in the case of Pyrgos, the concepts are relatively clear to identify, either inside the museum or in the settlement, and to build connections among them. The following indicative concept scheme (Figure 10) provides an overview of the museum's distinct thematic sections and how they are linked to some of the POIs located inside the settlement. Additionally, further connections are made through the interviews with the local craftsmen and habitats. The interviews help the team expose the professional relationship among the three main occupations referenced above and the master-apprentice training model. They are capable of depicting narratives and stories that facilitate understanding the social and cultural foundations of the settlement. The latter also constitutes the museum's scope. For example, the old smith told us about the strict training and progress of the younger smith, which is now the last smith of the village knowing how to make 
the marble craftsman's tools. Many aspects of intangible cultural heritage emerge from this example. For instance, the fact that he is the last carrier of the particular know-how certainly raises awareness of a tradition heading to oblivion.

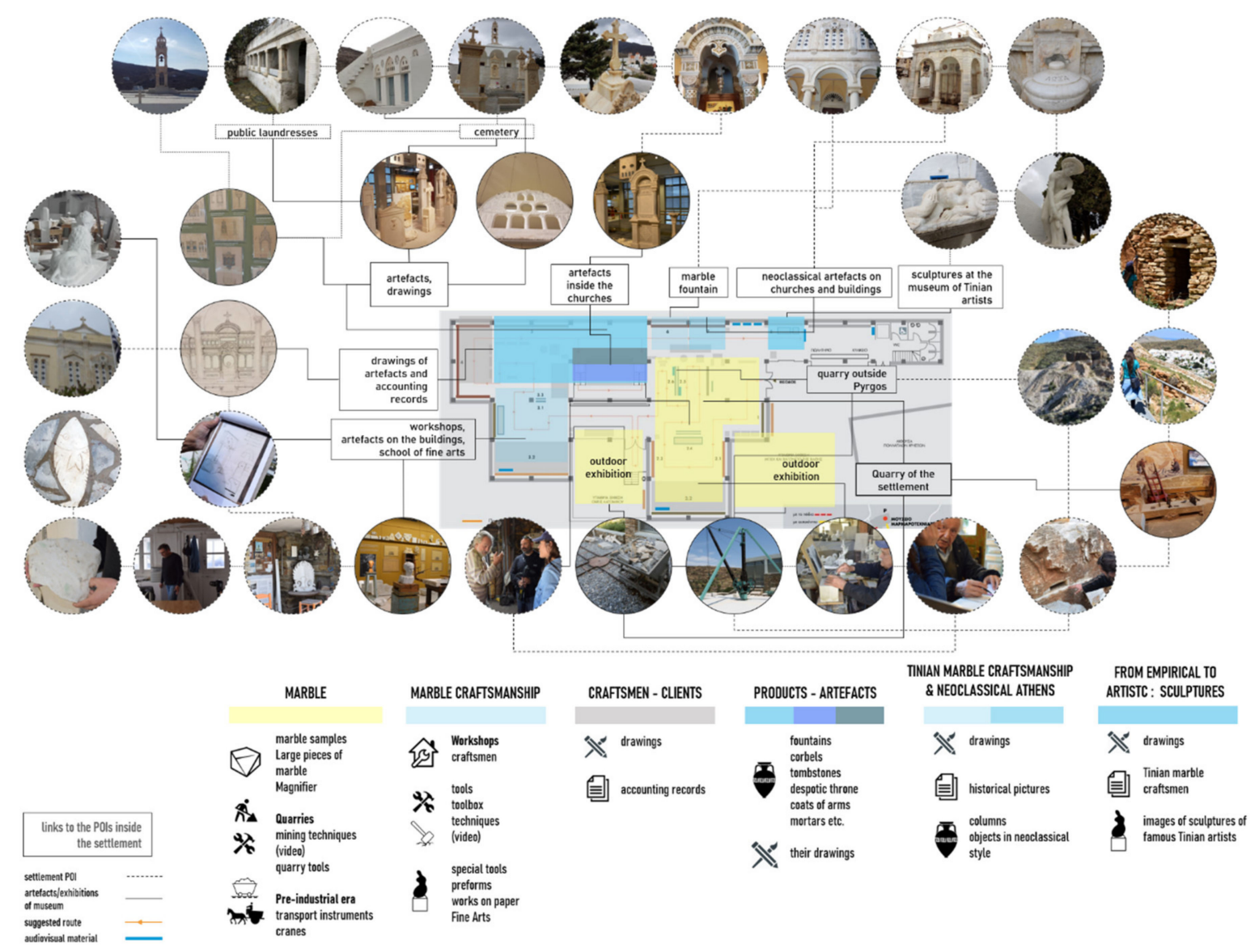

Figure 10. Museum of Marble Crafts thematic sections with their artefacts and exhibits. An indicative concept scheme of each section connected with an area of the settlement and its POIs.

Hence, the heatmap of Pyrgos physiognomy (Figure 6), combined with the concept scheme, informs the research and design teams about the unique points of architectural interest gathered in several areas of the settlement. These points have occurred during the study of the museum's content, the field documentation and visits, and the interviews conducted with settlement's museum curators and habitats. In specific, in Figure 11, the yellow-colored line passes from the marble fountain, a central POI and a frequent artefact found both in the settlement and at the museum sections, respectively. Moreover, interviews with artisans revealed local craftsmen's workshops as POIs inside the settlement, such as the old smith's workshop.

It is then acknowledged that contact with the museum's content-namely intangible cultural heritage and its material culture-its study and interaction with the local communal bodies, informed and enhanced the process of architectural heritage documentation, together with the literature review. Simultaneously, this methodology of documentation, when visualized through the digital tools, introduces the place's physiognomy, mapping suggested routes for the visitor to "catch the fleeting image" of the settlement. 


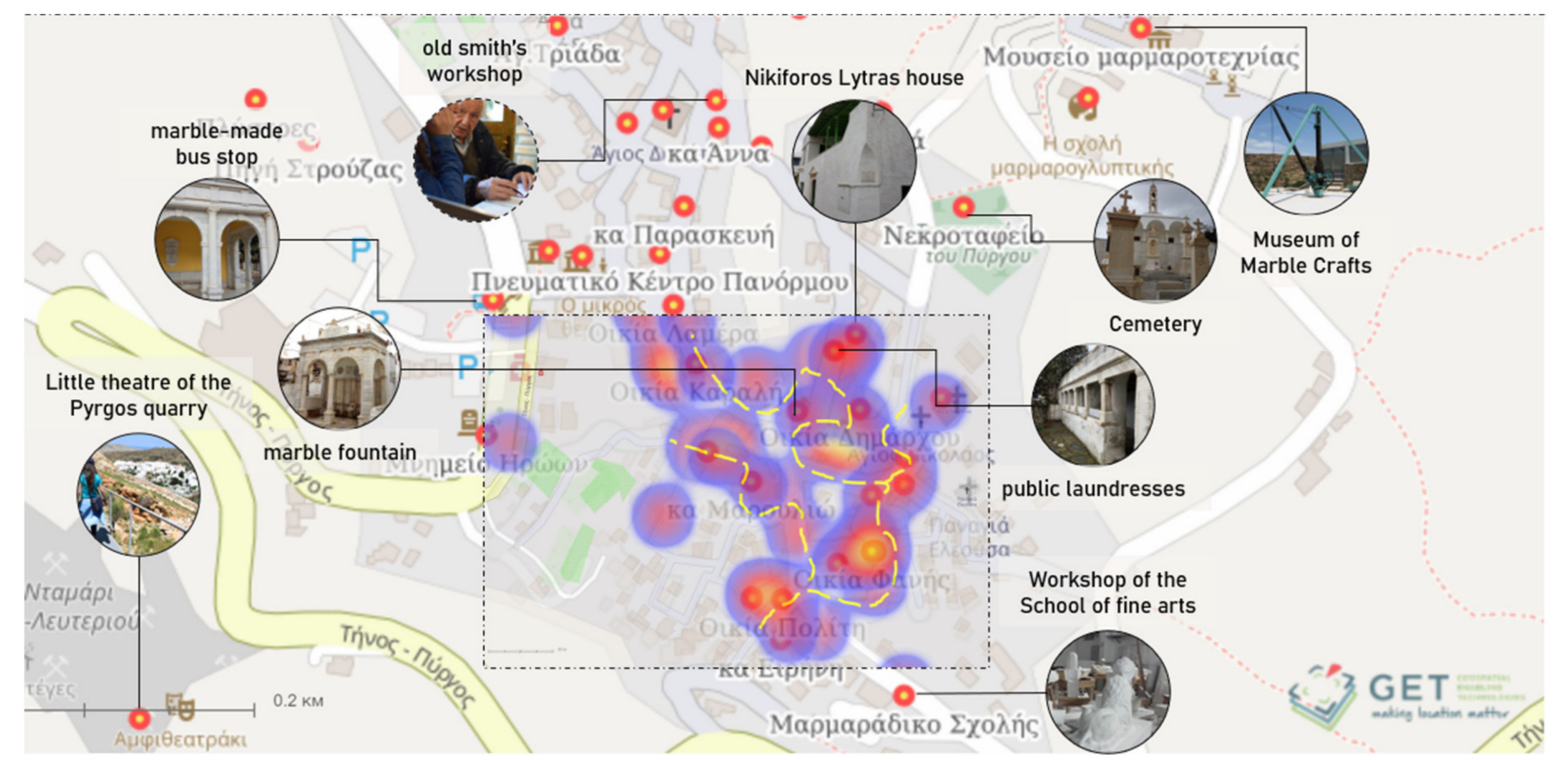

Figure 11. Indicative heatmap part of Pyrgos (Tinos) physiognomy placed upon historical buildings and POIs. The yellow-colored line proposes guided tours for visitors aiming to highlight the experience of the settlement's physiognomy.

\subsection{Concept Mapping of Agia Paraskevi and the Museum of Industrial Olive Oil Production (Lesvos Island)}

At the heart of the Mediterranean diet (inscribed at the UNESCO representative list of Intangible Cultural Heritage of Humanity) [47] is the use of olive oil. The island of Lesvos in Greece is renowned for its olives, and olive oil production dates back to antiquity [48-50]. Agia Paraskevi is a lowland town located in the center of the island, north of the Gulf of Kalloni, at an altitude of $100 \mathrm{~m}$. In its rural area, there are mountainous and semimountainous masses overgrown with olives or pines. The settlement is developed in a basin, surrounded by a ring formed by the low olive groves.

In contrast to other exclusively olive-producing villages in the area, people of this settlement used to cultivate cereals, grains, vines and other fruits and vegetables. At the same time, they were also occupied with animal husbandry (sheep and cattle), demonstrating abundance and self-sufficiency [51]. The simple geometric lines of the rural houses and the strict four-sided volumes of the church and the olive mills harmoniously contrast with the decorative surfaces of the urban type of mansions and the impressive school building, composing a graphic ensemble. Some of the special architectural features found are the cobblestones, the courtyards, the openings-skylights, inscriptions on the walls, the decorated floors inside the buildings, and the stairwells (Figure 12). In the case of Agia Paraskevi, contrary to Pyrgos, the connections between the intangible and tangible cultural heritage of the settlement are not as straightforward as marble craftsmanship. The reason lies in the subject. The cultivation of the olive tree and the production of olive oil indicate social and cultural activities that, contrary to marble and its crafts, are differently reflected upon in the buildings. 


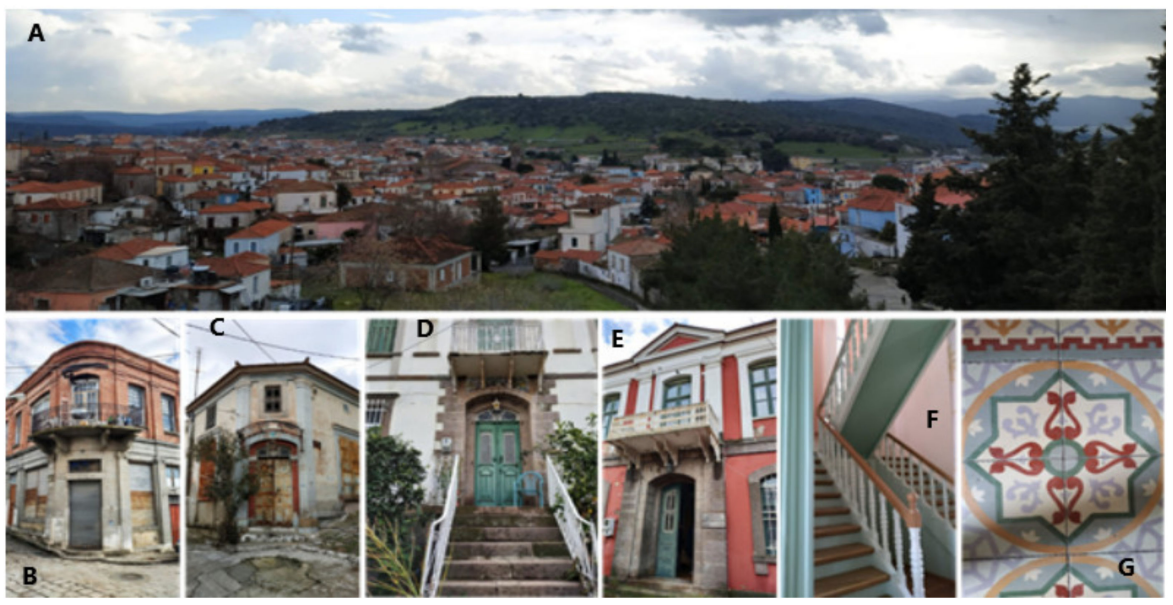

Figure 12. (A): The composed graphic ensemble of Agia Paraskevi. (B-G): Some of the special architectural and urban features inside the settlement.

At the settlement's entrance, we meet a small industrial zone with old and new factories and handicrafts. At the end of the 19th century, the economic demands and industrial evolution led the citizens to create a community's olive mill, the "people's machine". Since the main product was olive oil and its derivatives, the idea of the community olive mill grew into a driving force for the social, political, economic, and cultural advancement of the village and its citizens from 1911 till 1966 [52]. The industrial building has now been turned into a museum, the "Museum of Industrial Olive Oil Production of Lesvos", which seeks to promote and safeguard the industrial heritage of the place and to integrate it into the broader architectural, social, and cultural context of the time of its heyday period (Figure 13). Therefore, the museum is founded on a particular historical event that actively contributed to the settlement's physiognomy. It focuses on the progress and changes brought about by introducing mechanical movement and industrialization of the process of olive oil production, responding to the question "How did the inhabitants adapt and contribute to this technological and cultural shift?"
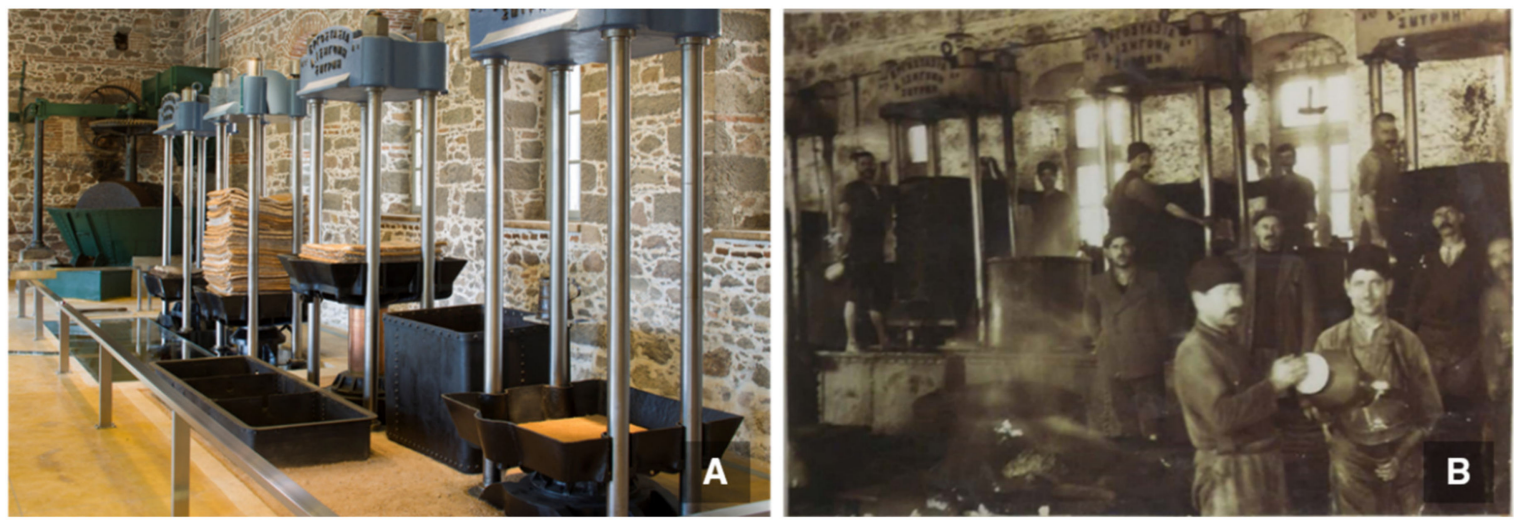

Figure 13. (A): Inside the main building of the Museum of Industrial Olive Oil Production of Lesvos, the "people's machine". (B): Old photo from the "people's machine" operating ${ }^{\circledR}$ piop.gr.

In particular, the first stages of olive oil production are presented in the main building. The nearby building functioned as a flour mill during the summer months when the olive mill was not operating. The other smaller buildings, used to serve as warehouses, host the mechanical equipment to produce propulsion works and showcase how the factory evolved from steam to diesel. Moreover, they present the settlement's history and its relation to the foundation of the "people's machine". During the Ottoman occupation, 
there was an intense trade union organization since certain professions defined the village's economy and set conditions that regulated work and organized the market. The foundation was an initiative of Agia Paraskevi's citizens in 1910, to secure financial resources for the community's educational and social deeds against the taxes and monopoly tactics of the corresponding private olive mills in the area [52].

Items, such as letters of support and financial aid, photos and descriptions of active community members found inside the museum, indicate how revolutionary and innovative the idea of community property has been for its time. Moreover, individual stories of personalities led the way, revealing the impact of the idea in the area's social fabric. Thus, the first connections arise from the role of the buildings themselves, either industrial or public or rural houses of crucial people, in shaping place's culture. For example, Agia Paraskevi's schools constitute an enormous public building of neoclassical architecture with a large courtyard. They bear European architecture elements showcasing the wealth and the influences from the oil exports and Mediterranean trade that many citizens were engaged. This impressive building, with the relatively disproportionate demographic size of the settlement, has a symbolic purpose. It signifies the importance of educational mechanisms on national and social emancipation. Other remarkable landmarks are the Perish Church, which bears evidence of Corinthian style and Ottoman baroque sculpted by Tinian marble craftsmen, the local fountains with arches of Islamic influence, the town hall that represents a typical urban residential building of the settlement, and the public bath (hamam) that also indicates the Ottoman cultural influence on the island. There is an artificial cave carved at the eastern foot of the hill, where today hosts the cemetery and the small sanctuary of the Saint Paraskevi. Other characteristic buildings inside the settlement are the mixed-use stores, dating at the end of the 19th century, where the ground floor was intended for shops while the first floor hosted policy clubs or associations [51,52], indicative of citizen involvement in public decision- making (Figure 14).
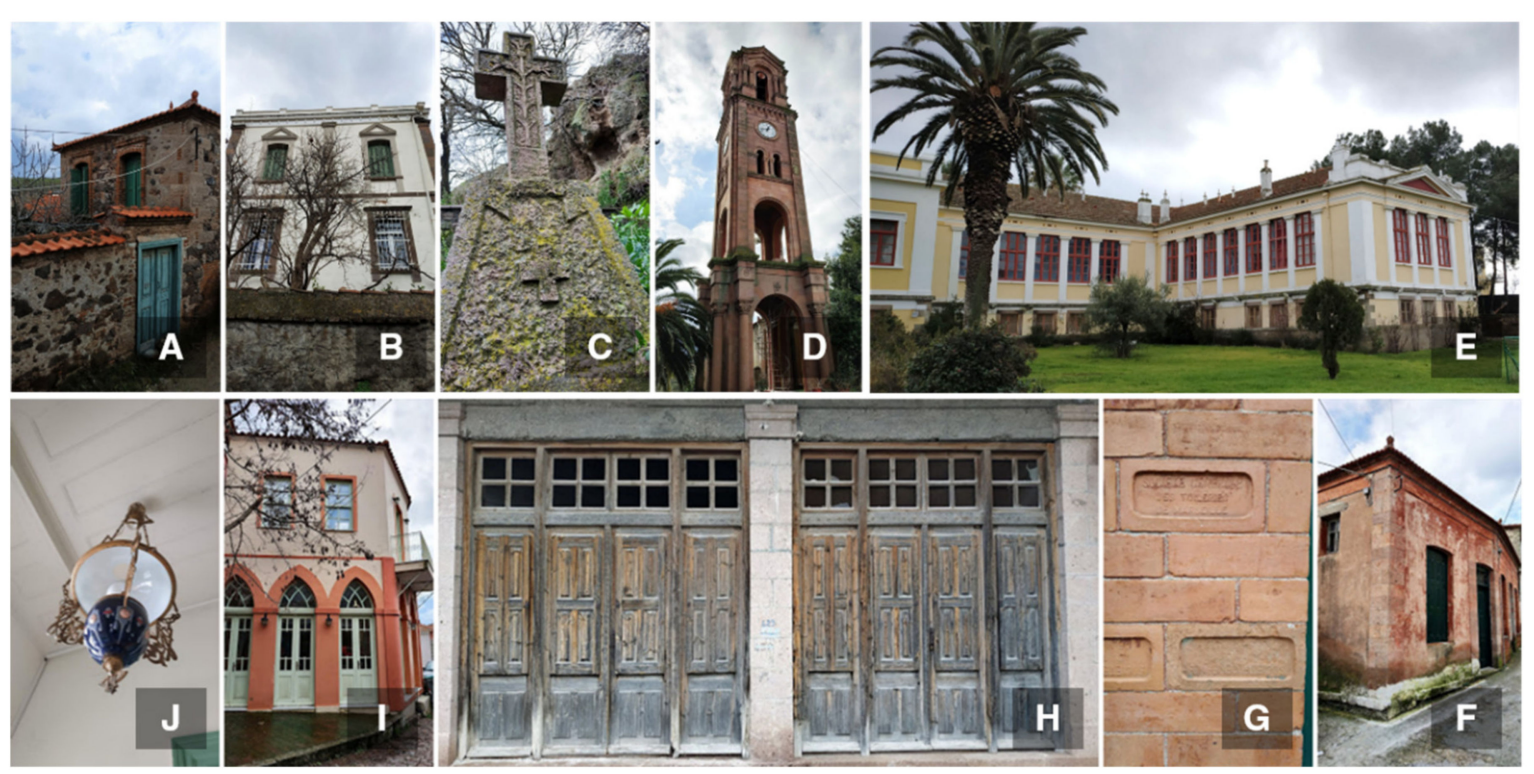

Figure 14. (A) Example of a rural house; (B) example of an urban house; (C) special engravings at the cemetery; (D) the steeple of the Parish Church; (E) the schools of Agia Paraskevi; (F) a warehouse; (G) engraved warehouse's bricks from Marseille, indicating the Mediterranean trade from the oil exports; $(\mathbf{H})$ a ground floor of a mixed-use store; (I) a mixed-use store which hosted the policy club "Omonoia"; $(\mathbf{J})$ indicative decoration from inside an urban building.

Subsequently, be it not so obvious, some connections arise between the historical facts and the settlement's industrial heritage. From the end of the 18th century to the beginning of the 20th, the story of the settlement is associated with the industrial heritage of the place depicted through the "people's machine", both the idea and the building. The idea also 
formed the social and cultural structures among its people. Policy clubs and associations attest to citizens' involvement in decision-making processes, and the public funding for the schools of Agia Paraskevi signifies the citizens' struggle for the community's educational and social deed. Maybe, the settlement buildings are the primary carriers of this heritage, both tangible and intangible. All buildings, industrial or urban, rural or public, churches and mixed-use stores, represent the (intangible) idea and its story that passed over this traditional scenic settlement.

As mentioned above, the connections between the museum's content and the settlement of Agia Paraskevi are not as apparent as in the case of Pyrgos. Nevertheless, the story of the "people's machine" unraveled settlement's history and some of its most outstanding buildings' use, purpose and story. Hence, connections lie in the historical and political events that occurred in the settlement and are associated with these buildings. Contrary to the Museum of Marble Crafts, this museum's thematic areas were not as helpful to facilitate the connections. Nevertheless, it was informative enough, providing direct communication with the local communal bodies to acquire a concrete view of the historical and political events related to the place's industrial heritage.

The exceptional architectural features studied during the Literature Review, helped understand the use of buildings and, in some cases, the story of buildings. Interaction with the citizens and the local folklore association shed more light on the stories of the buildings and their connections with the "people's machine", e.g., the first floor of a central mixed-use building is the association "Omonoia" and its active community members that initiated the idea of a community's olive mill. "Omonoia" is not depicted inside the museum as a building existing in the settlement. Therefore, the interaction with the communal bodies helped the team become aware of such connections between the story, as showcased inside the museum, and its influence on the image of the settlement. In that way, the mixed-use building becomes a POI in the settlement. (Figure 15).

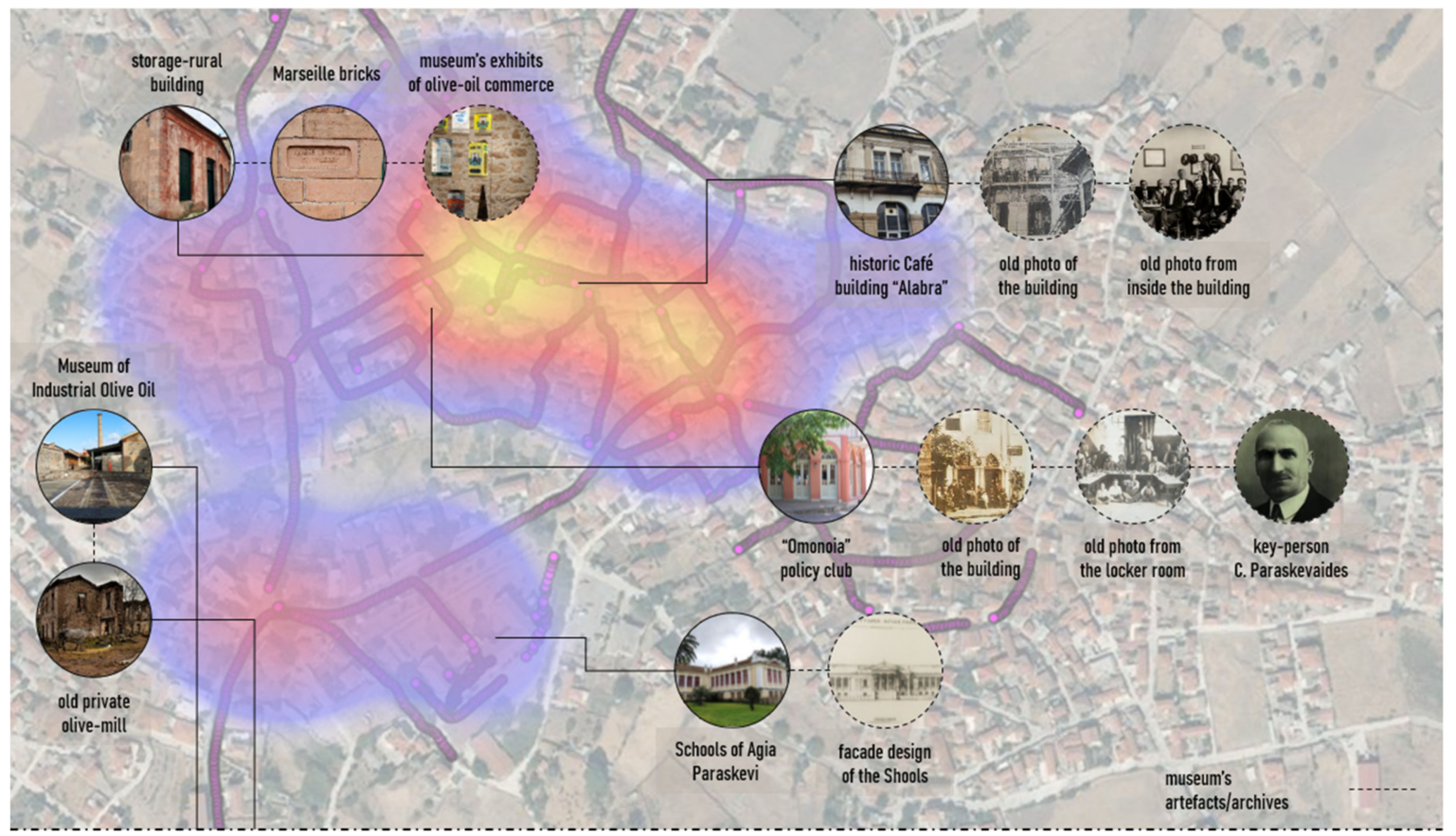

Figure 15. Heatmap of Agia Paraskevi (Lesvos) physiognomy, using historical buildings. Some indicative photos of the initial connections between tangible and intangible heritage are provided. One can spot that $360^{\circ}$ spheres are covering most of the area of blue and red zones, including the industrial buildings at the entrance of the settlement. 


\subsection{Concept Mapping of Olympoi and the Mastic Museum (Chios Island)}

Olympoi is one of the 22 villages of southern Chios, which are the only places in the world where the mastic tree or mastic-bearing skinos (Pistacia lentiscus var. Chia) is cultivated, extracting the mastic of Chios. The settlement was founded in the 14th century. It was formed during the island's occupation by the Genoese (1346-1566) and followed the principles of organizing a fortress-like residential system, a common feature applied in the lowland mastic-bearing area.

The shape of the settlement is four-sided, almost trapezoidal. The houses are connected and interconnected with each other forming a compact body. While the houses are constructed as a unit, their repetition creates the residential whole. The perimeter houses have no openings (doors and windows), confirming the functional character of a castle. At short distances, there are transverse covered ways that support the construction of the houses and domes in the covered ways that support the rooms. There were towers, "pyrgopoula" in the corners of the settlement, and the inhabitants could access the settlement through the two main gates. At the center stood the defensive tower, $20 \mathrm{~m}$ high, acting as a shelter for the inhabitants in case of attack. Individual architectural features found in the settlement are lintels, small arches, arches, "keys", loopholes, and ovens (Figure 16).
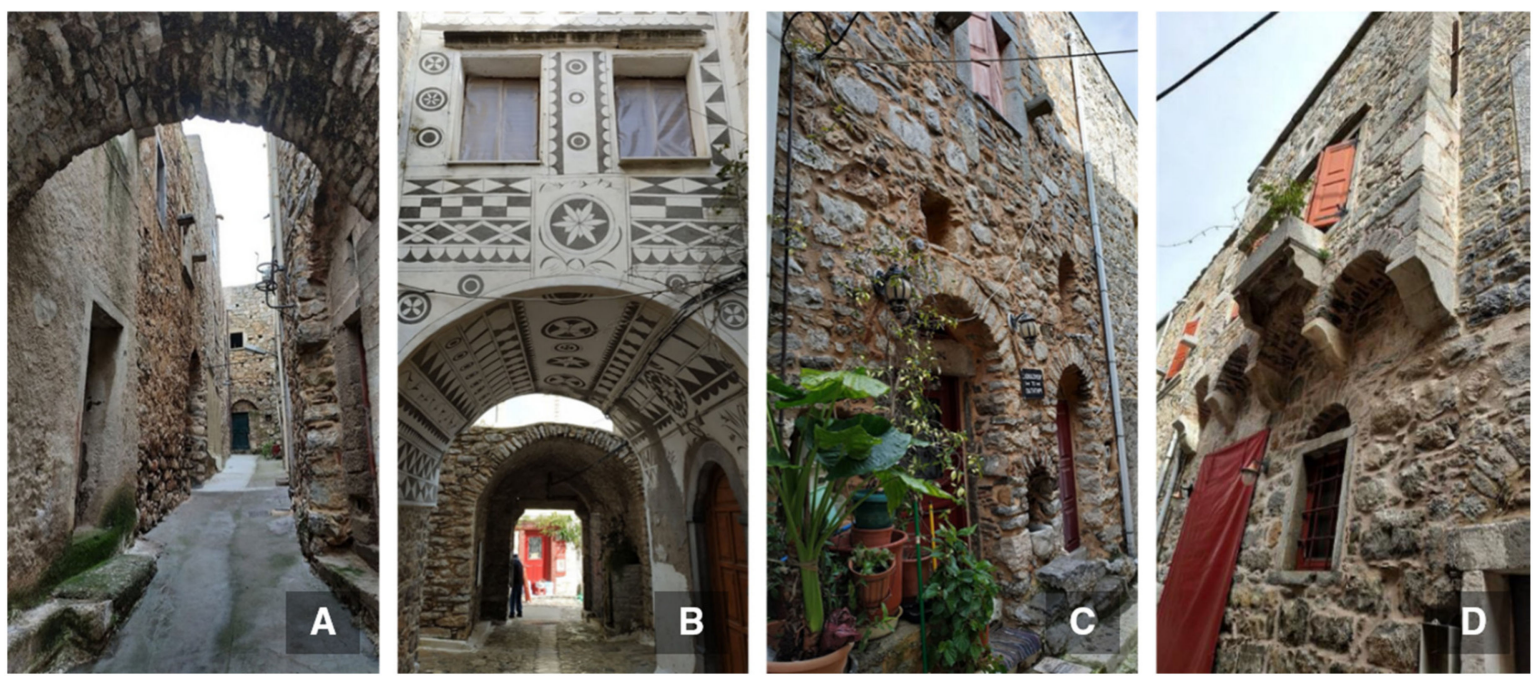

Figure 16. A few indicative architectural and urban features of Olympoi, a typical mastic village. (A) Transverse covered way; (B) dome in the covered way supporting a room; (C) examples of lintels above doors, small arches, loopholes, and extruded bricks playing the role of a freezer; (D) type of extruded balcony (sachnisi) with small arches.

Relevant to the case of Pyrgos, the case of Olympoi creates connections of intangible and tangible cultural heritage that are direct and relevant to the architectural heritage of the settlement. The fact that it is about mastic cultivation and mastic is the "precious tear", brought decisive changes in the settlement. From its very beginning, it determined the way of its construction. The settlement and the succession of sovereign regimes (Byzantine Empire, Genoese, Ottoman Empire) were "running" in parallel. Architectural elements of the settlement testify to the origin of the current regime, but this is more apparent to a wellread visitor or an architecture lover. Simultaneously, other more decisive structural changes (such as adding an upper floor to the original ground floor houses) result from changes in the commercialization regime of mastic and the privileges given to local cultivators during the Ottoman empire, for instance.

On the other hand, the museum deals with the mastic as the central product that determined, and still does, the life of its people (Figure 17A). The visitor can smell and touch the mastic tears exhibited at the entrance. Traditional songs, audiovisual material, and installations showcasing the essential cultivation tools and the works taking place either at the fields or inside the settlement by women, represent the museum's first sections. 
The following sections concern the product's recognition and how its trade management historically shaped the rural and inhabited landscape of southern Chios and the mastic villages. A part is dedicated to the village's architectural shape and how the several sovereign regimes influenced their type and physiognomy. This section also provides the 3D model of a traditional house with the relevant household equipment, and 3D model of the Olympoi village (Figure 17B). In the last two sections, visitors are informed about the cooperative exploitation and processing of mastic in modern times. As in the case of the "Museum of Industrial Olive Oil", this marks a new important chapter for the social, agricultural, industrial, and economic life of the mastic cultivators, the island itself, but also the productive history of mastic. As a result, there is extensive reference to the uses, thanks to which mastic travels worldwide. At the same time, the creativity and ingenuity of local producers and the way they promote their local heritage are also exhibited inside the museum.
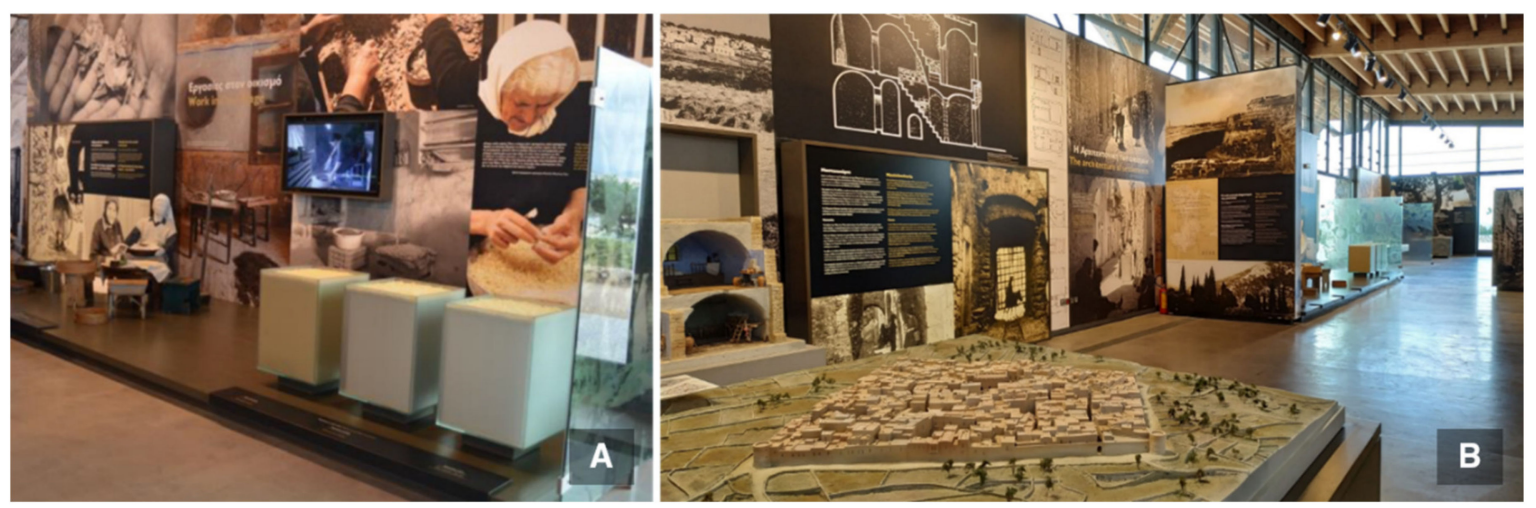

Figure 17. Inside the Chios Mastic Museum. (A) Indicative exhibition simulating the working tasks of mastic production taking place in the settlement. (B) Section dedicated to the architecture of the mastic villages, with the model of Olympoi settlement at the center.

As it is declared previously, the museum hosts the settlement of Olympoi in the form of a 3D model. This mastic village model is placed at the center of the section that deals with management and architecture, hence making the connection between the settlement and the museum content even more intuitive. However, this is not happening inside the settlement. The settlement itself does not "speak of" intangible cultural heritage. It has a small number of inhabitants to interact with and learn about the village's history and culture. Nevertheless, it becomes apparent that it is a medieval structure, related to a castle, with an iron gate, the main well, and a central tower taller than all the other residences. Hence, those are the first elements that a visitor should identify.

The architectural structure of the mastic village implies the need for easy and effective control of its habitats. Genoese acknowledged the rarity of the mastic and its cultivation. Inside this fortress, the valuable and somehow imprisoned mastic cultivators left the settlement through the iron gate en masse at sunrise for the fields, located to the highlands, and entered en masse at sunset. The narrow streets that lead to dead ends, the largest of which are named "platomata", give the impression of a maze aimed at controlling inhabitants and confusing intruders. The tower was tall enough to efficiently communicate with the beacons placed on the southern island's coastline to warn of pirate invasions. Nowadays, the narrow streets' dead ends have been turned into spaces where women of the settlement gather to sort the mastic tears and then clean them. Most of the wall is barely seen since posterior houses have covered its facade. The tower now has another touristic function while the churches are still in use, and some of them renovated. Nevertheless, the very architectural features are met inside the settlement. However, the connections with the intangible cultural heritage are boosted either via a visit at the Chios Mastic Museum or via the interaction with the inhabitants during their mastic-works at the village. 
In Figure 16, some POIs, such as the part of genuine wall, have been identified after an architectural tour offered by a local architect and mayor of the island. Interviews with a local cultivator and representatives of the Mastic Cooperation mostly informed us about the product's life cycle and some aspects of the living culture inside the mastic-villages. For instance, we were lucky enough to come across local women of the settlement sorting and cleaning mastic tears at outdoor gardens, "platomata", and outside houses. Additionally, in Figure 18, one can spot the $360^{\circ}$ spheres and evaluate that we still need to document more areas closer to blue and red zones. In addition, we need to register the POIs close to blue areas in the SDI portal, such as the intangible element of the sorting and cleaning works taking place at the dead ends and outside houses.

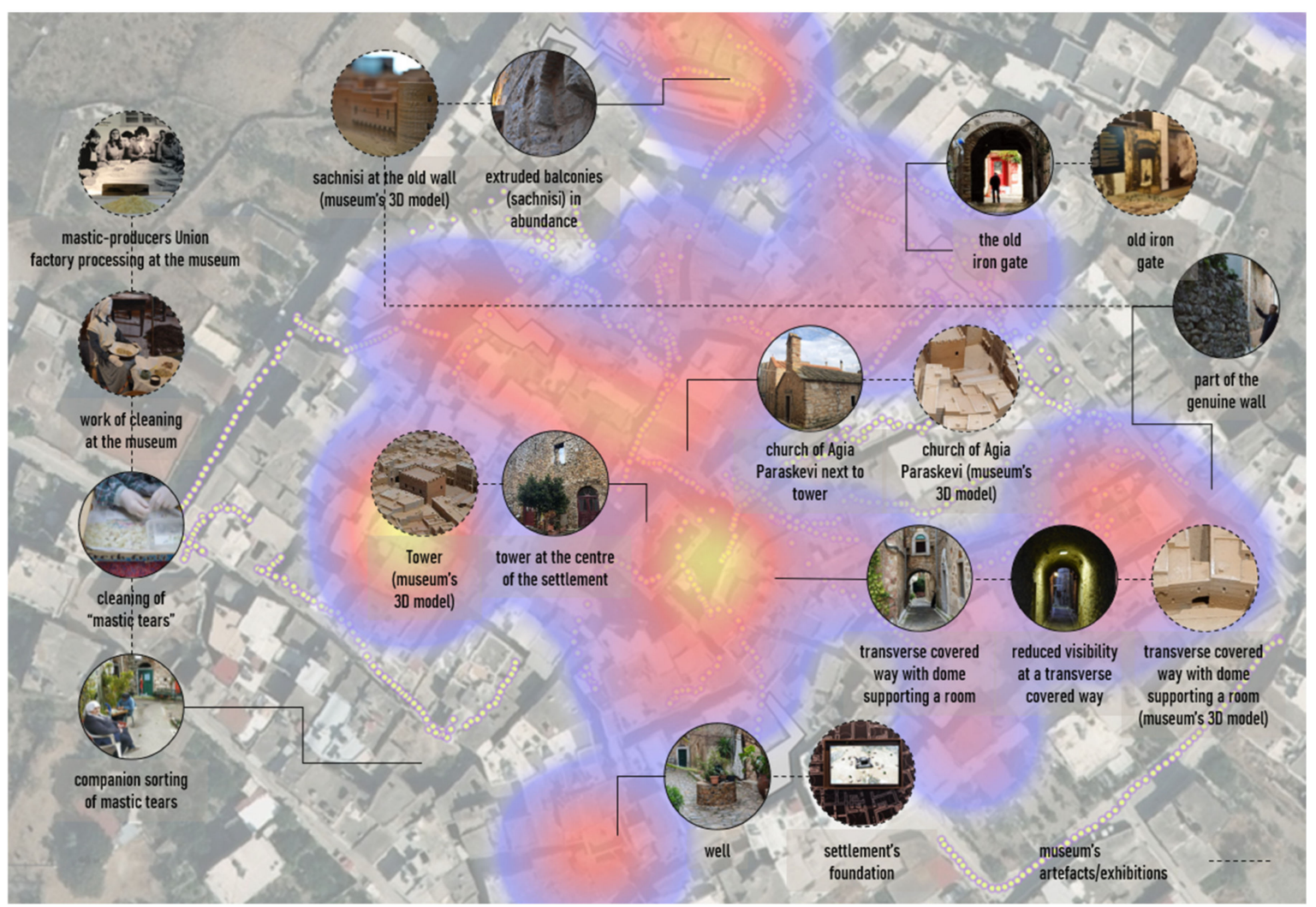

Figure 18. Heatmap of Olympoi (Chios) physiognomy, using only historical buildings. Indicative, yet unregistered to the SDI portal, POIs have been added to this scheme.

\section{Discussion}

The applied in this paper's methodological approach—HERMeS (v.1 and v.2)—has led to a number of research findings, conclusions, considerations, issues for future research and limitations concerning its application. Nevertheless, it is notable that it loomed up indications of how intangible cultural heritage is related to a place of architectural significance to reinforce its physiognomy. The most important indications are as discussed below:

The museum's curatorial content facilitated conceptual mapping schemes. The particular museums already have thematic sections of each settlement's intangible cultural heritage elements, which are adopted as the main categories of our conceptual maps developed in our methodological framework. Under these categories, new sub-categories are generated based on the connections with the settlement's architectural heritage, highlighting points and areas of interest. Due to its excellent documentation (awarded by Europa Nostra), the "Museum of Marble Crafts" creates such categories with higher immediacy to architectural heritage by exploiting the craftsmanship's material manifestations in the built space. It is the marble crafts that are so closely related to their intangible cultural heritage, 
the marble craftsmanship, know-how and, at the same time, the soul and the identity of the place. That is why Pyrgos, even more so than the other two traditional settlements, can be considered "a work of art". It is an issue of future research to delve deeper and reveal other spiritual, scientific, and psychological qualities, as well as sensorial, aesthetic, and logical perceptions, that contribute to the intense physiognomy of this place.

The closer the museum to the settlement, the greater the connections between the two. It is noticeable that the conceptual mapping scheme of Olympoi is still missing the connections with POIs, which emerge from intangible cultural heritage as inscribed and curated inside the museum, and as identified by the field visits. On the one hand, this problem might stem from the fact that we spent less time at our field visits and field documentation at Olympoi than at the other two settlements; hence our interaction with inhabitants was minimal. On the other hand, this museum is not part of the settlement, topologically. It is not even in close approximation, so that the museum's visitor can subsequently visit the settlement, as in the case of the other two, and vice versa. As a matter of fact, the settlement's visitor cannot effortlessly approach the museum and experience it as a continuity of the space, which seems to weaken the connections among intangible cultural heritage elements and their respective tangible manifestations during a visit and our fieldwork. In order to overcome this topological challenge, the design team has exploited the 3D model of Olympoi village inside the museum urging the visitors to explore the settlement. A similar direction should be followed in designing mobile tour applications - by using conceptual and heatmaps - to motivate tourists in Olympoi village to visit the respective museum.

Industrial heritage seems to function differently in providing connections with architectural heritage and intangible (cultural) heritage. Indeed, Agia Paraskevi has a different type of intangible heritage that seems to be not cultural, in the sense that it is not present or active anymore. However, it should be noted that the settlement once had a story where people's need for cumulative industrial legacy became an idea that was turned into the settlement's architectural heritage. This heritage is depicted upon its buildings-urban and industrial - as well as upon their purpose and use. Both urban and industrial acquire architectural heritage that denotes an era, an intangible heritage manifestation in space. This could be evidence in defining and considering how a monument inside a place could be enriched with authentic and significant industrial heritage.

An ontology base, integrated into the current geodatabase, could have produced a more informative concept map. A critical limitation of the current system architecture could be the emerging need to develop an ontology base for field documentation data. To that end, for example, a simple conceptual reference model for cultural heritage, such as CIDOC CRM [53], would allow and facilitate the connections of the various data presented in the conceptual mapping scheme of Pyrgos. Although it seems an effortless task, registering and editing such number of POIs is not sufficient to handle vast amounts of cultural heritage data [54]. Nevertheless, the current HERMeS SDI can host such an integration, and the research done so far is mature enough to delve into more structured relations and connections among the cultural heritage elements explored. The goal then, would be to inform the present research project's subsequent design phases and provide a sound foundation for other settlements to be recorded and connected with their intangible heritage. However, if the suggested integration could better be performed on-site by registering the intangible cultural heritage data with specific metadata fields, it would still require additional time spent at the lab to develop and refine the registered fields.

Usability evaluation of mobile recording application. The developed here HERMeS (v.1) mobile digital registration tool is addressed to architecture experts during their fieldwork. Therefore, the application needs to run a user study with the experts evaluating the mobile app's usability in the field and at the lab to render relevant feedback for future improvements or corrections regarding its efficiency and user's satisfaction.

The HERMeS methodology is being re-framed in the case of places with remarkable intangible (cultural) heritage. As it eventually turned out, the three traditional settlements 
have not only identified but also scientifically curated their intangible heritage through their respective museums. This fact facilitated the HERMeS architectural documentation significantly both during the first research stage and later on-site. Nevertheless, other places with rich cultural heritage may not always have the opportunity to curate their intangible heritage in such an efficient way. Consequently, our methodology should update its approach to consider the curatorial practices offered by the presented museums in pursuing dynamic documentation, curation, and dissemination of intangible (cultural) heritage in a cumulative way. Indeed, the curatorial practices introduced to us here seem to effortlessly and collectively bring together the community members that define the soul of the place. Thus, being close to the settlement helps these museums and the local communities, amongst others, to co-organize traditional festivals or workshops (e.g., "how to marble-craft" or "from olive to olive oil") for the museum and settlements' visitors. Likewise, Pyrgos and Agia Paraskevi's museum staff, who reside in the community, assisted the research team significantly by identifying valuable interview candidates among the community members. There were interviews that we felt like we were speaking to the soul of the place, as it happened with the cases of the old and the young blacksmiths in Pyrgos, as well as with the interviewee who used to help his father at the "people's machine", vividly and bodily recounting the working conditions of that time.

\section{Conclusions}

In the present article, we reported the initial phase of our research project "Mouseion Topos", concerning the architectural documentation of three significant traditional settlements of the Aegean region: Pyrgos of Tinos, Agia Paraskevi of Lesvos, and Olympoi (mastic village) of Chios. Each settlement is associated with a museum showcasing the related and worldly-recognized (by UNESCO), intangible cultural heritage. Respectively, these are the "Museum of Marble Crafts" in Pyrgos, the "Museum of Industrial Olive Oil Production" in Agia Paraskevi, and the "Chios Mastic Museum" in mastic-villages. The outcome of this research phase is to testify the effectiveness of the HERMeS (v.1 and v.2) methodology, to inform about the obtained data for the design teams to rethink in the early design stages of interactive applications, particularly in the case of mobile tours. Towards this direction, the geospatial information gathered through the architectural documentation is combined with conceptual mapping schemes attempting to connect the museum's content with the settlement's points of interest, which, together with the representative buildings, provide an informed understanding of the settlement's physiognomy.

According to the research findings, the study of intangible cultural heritage, as the three museums curated it, provided the project team with the first glimpse of "what has happened" in each place, respectively. In turn, a walk and wandering inside the settlement started giving the first "fleeting image" of the place. However, the connections among the visible cultural heritage data with the intangible cultural heritage presented at the museum were not similarly evident in each settlement. Additionally, it becomes clear that to acquire a better understanding and define the elements that sculpted the image of the place, it still requires time and collecting of multiple points of view. The study of the architectural heritage and physiognomy of a place gives a first approximation to this end; however, this is an issue for future research. Moreover, research findings support that the systematic study of the life of people and history of a place through the museums' archives, the interaction with the inhabitants during the fieldwork-especially in Agia Paraskevi-the reflection on data obtained from on-site recording of buildings with the project team and the museums' curators, as well as the systematic organization of the data in HERMeS SDI portal, can provide and build connections between a place's tangible and intangible cultural heritage. These connections are only depicted through the various conceptual and heatmaps created among the researchers of this project within the HERMeS methodology framework and its updated version 2.

It is apparent that the future design of interactive applications and research through design approaches must ensure that the connections made by the project team will be 
delivered to the visitors to acquire the physiognomy of the place. Indicative attempts of this approach are already found in relative literature $[55,56]$. However, future research is necessary in order to provide visitors and users of interactive applications with such a touring experience, embarking upon a journey that will encourage them to wander around the settlement and search for the individual material manifestations of intangible heritage. Nonetheless, it could be argued that the design approach should shift from user-centric to human-centric and pursue the very humanitarian aspects that can bring people closer to the elements of everyday life that they are primordially connected with. Tangible and intangible cultural heritage is inherently present around us, even if we are merely too preoccupied to perceive them. Our research method and findings contribute both to strengthen places' physiognomy, connections of tangible and intangible cultural heritage, and reinforce visitors' experience.

Author Contributions: Conceptualization, P.C., T.V. and V.N.; methodology, P.C. and V.N.; system development, P.C. and T.V.; writing-review and editing, P.C., V.N., T.V., S.V. and P.K. All authors have read and agreed to the published version of the manuscript.

Funding: This research has been co-financed by the European Union and Greek national funds through the Operational Program Competitiveness, Entrepreneurship, and Innovation, under the call RESEARCH—CREATE-INNOVATE (project code: T1EDK-15171).

Institutional Review Board Statement: Not applicable.

Informed Consent Statement: Not applicable.

Data Availability Statement: Data available at https:/ / sdi.mouseion-topos.getmap.gr / (accessed on 27 November 2020).

Acknowledgments: We would like to thank the National Technical University of Athens (NTUA) for their contribution, in particular, the course "Architectural Design 5A: Architectural Analysis of Traditional Buildings and Ensembles" and the responsible professor of the Department of Architecture of NTUA, Eleni Maistrou.

Conflicts of Interest: The authors declare no conflict of interest.

\section{References}

1. Srinivas, S.; Smart, A. Landscapes of Urban Memory: The Sacred and the Civic in India's High-Tech City; University of Minnesota Press: Minneapolis, MN, USA, 2001.

2. Warf, B.; Arias, S. The Spatial Turn: Interdisciplinary Perspectives; Routledge: London, UK, 2008.

3. Stefanou, J.; Stefanou, I. Description of the image of the city. In The Outlines: Basic Elements for Determining the Physiognomy of Places; University Publications NTUA: Athens, Greece, 1999.

4. Kirillova, K.; Fu, X.; Lehto, X.; Cai, L. What makes a destination beautiful? Dimensions of tourist aesthetic judgment. Tour. Manag. 2014, 42, 282-293. [CrossRef]

5. Chapman, E.H.; Lynch, K. The Image of the City. J. Aesthet. Art Crit. 1962, 21, 91. [CrossRef]

6. Ingold, T. The Perception of the Environment, Essazys on Livelihood, Dwelling and Skill; Routledge: London, UK, 2002.

7. Ioannides, M.; Ioannidis, C.; Enkleistriotis, A.N.; Castrillo, D.; Chatzigrigoriou, P.; Papageorgiou, E.; Leventis, G.; Nikolakopoulou, V.; Athanasiou, V.; Bourexis, F.; et al. Towards Monuments' Holistic Digital Documentation: The Saint Neophytos Enkleistriotis Case Study. In Lecture Notes in Computer Science; Metzler, J.B., Ed.; Springer: Berlin, Germany, 2016; Volume 10058, pp. $442-473$.

8. Alivizatou, M. Intangible Heritage and the Museum: New Perspectives on Cultural Preservation; Routledge: London, UK, 2016.

9. Kirshenblatt-Gimblett, B. Intangible Heritage as Metacultural Production1. Mus. Int. 2004, 56, 52-65. [CrossRef]

10. Smith, L.; Akagawa, N. Intangible Heritage; Routledge: London, UK, 2008.

11. Phillips, R. Re-Placing Objects: Historical Practices for the Second Museum Age. Cult. Musees 2016, 28, 117-149. [CrossRef]

12. Munjeri, D. Tangible and Intangible Heritage: From difference to convergence. Mus. Int. 2004, 56, 12-20. [CrossRef]

13. Piraeus Bank Group Cultural Foundation. Available online: https://www.piop.gr/en/ (accessed on 28 October 2020).

14. Chatzigrigoriou, P. Taking the next step in digital documentation of historic cities: How hermes evolved in an open data digital library of historic buildings. In Proceedings of the 6th International Euro-Mediterranean Conference on Digital Heritage, EuroMed 2016, Nicosia, Cyprus, 31 October-5 November 2016.

15. Earl, J.; Saint, A. Building Conservation Philosophy; Routledge: London, UK, 2015.

16. Fielden, B.M.; Weaver, M.E.; Matero, F.G. Conserving Buildings: Guide to Techniques and Materials. Stud. Conserv. 1994, $39,215$. [CrossRef] 
17. The Athens Charter for the restoration of historic monuments. In Proceedings of the 1st International Congress of Architects and Tech-nicians of Historic Monuments, Athens, Greece, 11 October 1931.

18. Stefanou, J. The Urban Planning of Hermoupolis, Academice; National Technical University: Athens, Greece, 2003.

19. Hassler, U. Implications of climate change on heritage. Build. Res. Inf. 2006, 34, 175-179. [CrossRef]

20. Stefanou, J. The Concept of the Monument and the Ideology of its Protection; National Technical University of Athens: Athens, Greece, 1985. (In Greek)

21. Papalexopoulos, D.; Kalafati, E.; Papadopoulos, S. Building memory. In Proceedings of the 2001 Conference on Virtual Reality, Archeology, and Cultural Heritage, Glyfada, Greece, 28-30 November 2001; pp. 27-32.

22. Vecco, M. A definition of cultural heritage: From the tangible to the intangible. J. Cult. Heritage 2010, 11, 321-324. [CrossRef]

23. Ahmad, Y. The Scope and Definitions of Heritage: From Tangible to Intangible. Int. J. Heritage Stud. 2006, 12, 292-300. [CrossRef]

24. Bouchenaki, M. A major advance towards a holistic approach to heritage conservation: The 2003 Intangible Heritage Convetion. Int. J. Intang. Herit. 2007, 2, 106-109.

25. Tomaszewski, A. Tangible and intangible values of cultural property in Western tradition and science. In Proceedings of the 14th ICOMOS General Assembly and International Symposium: 'Place, Memory, Meaning: Preserving Intangible Values in Monuments and Sites', Victoria Falls, Zimbabwe, 27-31 October 2003.

26. Riegl, A. The Modern Cult of Monuments: Its Character and Its Origin; MIT Press: Cambridge, UK, 1982; Volume 25, pp. 20-51.

27. Rodwell, D. Sustainability and the Holistic Approach to the Conservation of Historic Cities. J. Arch. Conserv. 2003, 9, 58-73. [CrossRef]

28. UNESCO Tinian Marble Craftsmanship. Available online: https://ich.unesco.org/en/RL/tinian-marble-craftsmanship-01103 (accessed on 28 October 2020).

29. UNESCO Know How of Cultivating Mastic on the Island of Chios. Available online: https://ich.unesco.org/en/RL/know-howof-cultivating-mastic-on-the-island-of-chios-00993 (accessed on 28 October 2020).

30. Lefas, P. Architecture and Inhabitation: From Heidegger to Koolhaas; Plethron: Athens, Greece, 2008.

31. Alivizatou-Barakou, M.; Kitsikidis, A.; Tsalakanidou, F.; Dimitropoulos, K.; Giannis, C.; Nikolopoulos, S.; Al Kork, S.; Denby, B.; Buchman, L.; Adda-Decker, M.; et al. Intangible Cultural Heritage and New Technologies: Challenges and Opportunities for Cultural Preservation and Development. In Mixed Reality and Gamification for Cultural Heritage; Metzler, J.B., Ed.; Springer: Berlin, Germany, 2017; pp. 129-158.

32. Dovey, K. Becoming Places: Urbanism/Architecture/Identity/Power; Routledge: London, UK, 2009.

33. Schulz, N. Genius Loci: The Spirit of the Place: For a Phenomenology of Architecture; Frangopoulos, M., Ed.; University Publications NTUA: Athens, Greece, 2009.

34. Maistrou, H. Analysis of Urban Patterns in Historic Settlements, as Basis for Their Conservation and Planning. In European Research on Cultural Heritage: State of the Art Studies; Drdácký, M., Ed.; Institute of Theoretical and Applied Mechanics Academy of Sciences of the Czech Republic: Prague, Czech Republic, 2006; Volume 4, pp. 233-237.

35. Kolko, J. Abductive Thinking and Sensemaking: The Drivers of Design Synthesis. Des. Issues 2010, 26, 15-28. [CrossRef]

36. Novak, J.D.; Cañas, A.J. The Origins of the Concept Mapping Tool and the Continuing Evolution of the Tool. Inf. Vis. 2006, 5, 175-184. [CrossRef]

37. Dong, M.; Kleinsmann, S.; Deken, F. Investigating design cognition in the construction and enactment of team mental models. Des. Stud. 2013, 34, 1-33. [CrossRef]

38. Bofylatos, S.; Spyrou, T. A four layer of abstraction communication framework supporting design dialogue. In Proceedings of the 11th European Academy of Design Conference: The Value of Design Research, Paris, France, 22-24 April 2015.

39. Badke-Schaub, P.; Neumann, A.; Lauche, K.; Mohammed, S. Mental models in design teams: A valid approach to performance in design collaboration? CoDesign 2007, 3, 5-20. [CrossRef]

40. Chatzigrigoriou, P. Can we use GIS as a historic city's heritage management system? The case study of Hermoupolis-Syros. In Proceedings of the 4th International Conference on Remote Sensing and Geoinformation of the Environment, Paphos, Cyprus, 4-8 April 2016; p. 96880S.

41. Florakis, A.E. Museum of Marble Crafts, Guidebook; Piraeus Bank Group Cultural Foundation: Athens, Greece, 2009.

42. Mergos, G.; Patsavos, N. Cultural Heritage and Sustainable Development: Economic Benefits, Social Opportunities and Policy Challenges; Technical University of Crete: Chania, Greece, 2017.

43. Florakis, A.E. Tinian Marble Sculpture: History and Technique; Piraeus Bank Group Cultural Foundation: Athens, Greece, 2008.

44. Haritonidou, A. Greek Traditional Architecture, Tinos; Melissa: Athens, Greece, 2001.

45. Pereira, D.; Eynde, V.C.V.D. Heritage Stones and Geoheritage. Geoheritage 2019, 11, 1-2. [CrossRef]

46. Habibi, T.; Ponedelnik, A.A.; Yashalova, N.N.; Ruban, D.A. Urban geoheritage complexity: Evidence of a unique natu-ral resource from Shiraz city in Iran. Res. Policy 2018, 59, 85-94. [CrossRef]

47. UNESCO Mediterranean Diet. Available online: https://ich.unesco.org/en/RL/mediterranean-diet-00884 (accessed on 28 October 2020).

48. Kontis, P. Lesvos and Its Minor Asiatic Region; Athens Technological Organization-Athens Centre of Ekistics (in Greek) Athens Center of Ekistics: Athens, Greece, 1978; pp. 22-46.

49. Marathianou, M.; Kosmas, C.; Gerontidis, S.; Detsis, V. Land-use evolution and degradation in Lesvos (Greece): A histor-ical approach. L. Degrad. Dev. 2000, 11, 63-73. [CrossRef] 
50. Sifneos, A. On entrepreneurs and entrepreneurship of the olive-oil economy in the Aegean: The case of Lesvos island. Hist. Rev. Rev. Hist. 2004, 1, 245-273. [CrossRef]

51. Paraskevaides, C. The Old Agia Paraskevi of Lesvos; Agia Paraskevi Community Cultural Center of Lesvos: Agia Paraskevi, Lesvos, 1991.

52. Sifneos, E. Industry and Communitarianism-The "People's Machine" in Agia Paraskevi, Lesvos; Piraeus Cultural Foundation: Athens, Greece, 2007.

53. Definition of the CIDOC Conceptual Reference Model. Available online: http://www.cidoc-crm.org/sites/default/files/2018-1 0-26\%23CIDOCCRM_v6.2.4_esIP.pdf (accessed on 29 November 2020).

54. Kim, H.; Matuszka, T.; Kim, J.-I.; Kim, J.; Woo, W. Ontology-based mobile augmented reality in cultural heritage sites: Information modeling and user study. Multimedia Tools Appl. 2017, 76, 26001-26029. [CrossRef]

55. Vosinakis, S.; Nikolakopoulou, V.; Stavrakis, M.; Fragkedis, L.; Chatzigrigoriou, P.; Koutsabasis, P. Co-Design of a Playful Mixed Reality Installation: An Interactive Crane in the Museum of Marble Crafts. Heritage 2020, 3, 1496-1519. [CrossRef]

56. Koutsabasis, P. Learning about the Heritage of Tinian Marble Crafts with a Location-Based Mobile Game and Tour App. In Proceedings of the Euro-Mediterranean International Conference on Digital Heritage, Online, 2-5 November 2020. Under Publication. 